\title{
Timeflow: How Consumption Practices Shape Consumers' Temporal Experiences
}

\author{
NIKLAS WOERMANN \\ JOONAS ROKKA
}

\begin{abstract}
While the importance of the temporal dimension for both positive and negative consumption experiences has been well understood, no general theory exists to explain how consumers' temporal experiences come about. We theorize temporal experiences as an effect of performing consumption practices in order to move from assessing isolated contextual variables to a more holistic understanding. The timeflow of a practice is defined as its ability to evoke an experienced temporality that cannot be reduced to either subjective "inner" time or cosmic "outer" time. On the basis of a longitudinal ethnography of temporality in two lifestyle sportsfreeskiing and paintball—we find that five practice elements shape temporal experience: material set-up, bodily routines and skills, teleoaffective structures, rules, and cultural understandings. Misalignments of practice elements induce experiences of temporal drag or rush associated with experiences such as boredom and stress. We contribute to prior research on consumption experiences, waiting, and servicescapes.
\end{abstract}

Soon, it is my turn. The waiting will be over. Damn. Under different circumstances, I can hardly endure queuing, impatiently keeping myself busy until finally being first in line. But this time, I wish I could keep waiting a little longer. Keep standing here, in line with fellow freeskiers on the slope some 50 meters above the massive snow ramp. Keep watching others as they descend down toward the kicker, then swiftly ski through the transition before leaping into the air, performing rapid successions of somersaults, or perhaps multiple rotations. How will my own descent end? I will find out soon enough-too soon in fact! So I try to relax by shaking my arms and legs a bit, sucking in a deep breath of cold Alpine air. "I will be OK, so just let it happen already; trust your skill, your equipment, and the designers of the ramp!" No time to hesitate. I grab my ski poles a little more tightly and push myself over the edge. "Here I come!" The first moments of acceleration are just fine, but although I go faster and faster, the kicker hardly seems to approach me. The wind begins hissing in my ears. This is taking way too long. My stomach tenses as I feel the acceleration dragging me downward. I stare at the kicker in front of me as I speed toward it. Then the moment vanishes, and suddenly the ramp is a wall of snow towering in front of me. I push back against the compression of my knees, caused by the transition, and zoom up the ramp. As I jump I spread out my arms and rotate my torso forcefully to the left, causing a full rotation while I sail through the air. For a brief moment, time freezes as I become weightless. I am now a 
passenger of my body much more than an actor. I watch the snow-covered surroundings slowly swirl around me as I frantically try to keep my balance. Suddenly, the moment of weightlessness is over, and I am sucked back down to the ground. Luckily the landing zone appears before my eyes just an instant before the inevitable impact. I hear a loud Whumb! as my skis smack onto the snow, and the force of the impact jars my body. Before I know it, I am already a few meters below the landing zone and I brake with my skis. A wave of euphoria floods through my body. I made it! (Field note from a training session, Penken Park, Mayrhofen, Austria)

$\mathrm{T}$ emporality is a fundamental dimension of life and an unavoidable aspect of consumer behavior (Cotte, Rathneswar, and Mick 2004; Feldman and Hornik 1981; Hirschman 1987; Hornik 1984; Shove, Trentmann, and Wilk 2009; Taylor 1994). However, as this field note about the lifestyle sport of freeskiing illustrates, time is not only a frame within which consumption takes place at a particular time or in intervals but an inherent feature of the consumption experience itself. The quote suggests that time is neither solely an abstract and external physical dimension nor a universal, homogenous stream but is immediately and intensely felt. It is directly intertwined with breathing, fearing, moving about, and being there. Inescapable and sometimes overwhelming in positive or negative ways, temporal experience functions as a mediator of the quality and attractiveness of a market offering (Arnould 2005).

As a phenomenon, temporality is important in a variety of consumer research and practitioner contexts. Consumers may, for instance, lie happily on the beach for hours despite (or perhaps because of) the uneventfulness of the activity but be impatient and frustrated after mere minutes of waiting in line (Kellaris and Kent 1992; Maister 1985; Taylor 1994). Likewise, marketers design themed retail spaces to prevent shopping experiences from becoming hectic and thus stressful but also to preclude uneventfulness and thus potential boredom (Arnould 2005; Baker and Cameron 1996; Kozinets et al. 2004). In the same vein, entertainment products such as movies, services like rafting (Arnould and Price 1993), and sports such as skydiving (Celci, Rose, and Leigh 1993) or motocross (Martin and Schouten 2014) purposefully induce sudden changes in pace or tempo that keep consumers captivated without stressing them too much. These cases show that consumption activities evoke certain temporal experiences for those taking part, and that experienced temporality can be an important factor for consumer attitudes, wellbeing, or willingness to consume. What is amiss in the literature, however, is a theoretical model that links temporal experiences to the consumption practices bringing them about. The consumption of fast food offers an example. Surely its global success is not due merely to the quality of the food. Rather, the very "fastness" of eating fast food seems to add a crucial benefit or fulfill an essential consumer need or want. The question is thus whether "fast- ness" can be reduced to mere economic efficiency such as time-saving benefits, or whether consumers also indulge in a quick bite simply for the rush (Gleick 1999; Ritzer 1999). Interestingly, consumers increasingly opt for "slow food" or join the movement toward "slow living" (Honore 2004; Parkins 2004; Pink 2007).

In this article, we propose a theoretical framework for capturing and conceptualizing the "fastness" or "slowness" of consumption practices and explain how these two characteristics emerge and change. We do so by introducing the notion of the timeflow of consumption practices, defined as a practice's ability to induce a certain pattern of experienced temporality in those performing the practice.

Our framework builds on the idea that social practices are routinized ways of doing that are the building blocks of social life, ranging from very common activities like talking, walking, or eating to highly specialized pursuits like performing freestyle skiing tricks (Reckwitz 2002a; Schatzki 2002). Practices consist of elements such as material setup, bodily skills and routines, teleoaffective structures, rules, and cultural understandings that are being integrated when the practices are performed (Shove, Pantzar, and Watson 2012). In our view, performing a certain practice envelops practitioners in a phenomenal field (Merleau-Ponty 1962). The performance evokes a certain experience, and the temporal dimension of the phenomenal field is shaped by the timeflow of the practice. We contend that all consumption practices have timeflows that in general are pervasive, relevant to consumers, and relatively stable.

Consumers routinely and systematically seek consumption experiences that are made attractive by a particular temporal flow, such as music genres characterized by different tempi. One example is clubbers indulging in ecstatic soundscapes of bass music: "over the course of the night the music changed tempo, varying from warm-up club 'anthems' to heavier 'hard core' house at the peak of the evening, to the trance like softer sounds that accompany the 'chill out' period that signals the end of the evening" (Goulding et al. 2009, 763). Or consider the hectic experience of adrenalin-drenched free-fall among skydivers: "You get a lot of fun out of it, but there is something fast-paced. You're thinking in split seconds. Everything seems to be in a time warp. Everything slows down. It's total concentration" (Celci et al. 1993, 8). These examples illustrate a fundamental point: the temporality of a consumption practice does not equate to its temporal duration. Clubbers listen to "fast" music for hours, while a few minutes of meditative sounds might open up a brief but reinvigorating "short eternity" of relaxation. For this reason, we introduce new ways of thinking about temporality by examining how experiential qualities of temporality are inherently connected with consumption practices.

Until now, experienced temporality has been conceptualized in two ways in the literature. On the one hand it is universalized, such that measured durations of universal or absolute time are equated with corresponding consumer perceptions of duration (Hornik 1984; Katz, Larson, and Larson 
1991; Kellaris and Kent 1992; Taylor 1994). On the other hand, it is subjectivized and internalized, in that temporal perception is discussed as an individual mental process prefigured by individual timestyles (Bergadaà 1990; Cotte et al. 2004; Feldman and Hornik 1981; Usunier and ValetteFlorence 2007). We claim that both prior research and everyday understanding of temporal scapes such as the rush of an airport or the tranquility of a park suggest otherwise: consumers engaged in similar activities in similar places share very similar temporal experiences.

We call this previously established phenomenon timeflow. The aim of this article is to tie temporal experiences evoked by timeflow to consumption practices, instead of tying these experiences either to universal wholes like cultures or the society or to individual traits or unique events. In the sections that follow, we seek to $(a)$ sensitize (Epp and Price 2008) and orient consumer researchers to the ability of consumption practices to induce shared temporal experiences; (b) empirically detail the nature of timeflow and how it is shaped by five different elements of consumption practices by examining two cases; $(c)$ theorize a comprehensive model that explains negative temporal experiences of drag or rush as an effect of the misalignment of practice elements; and (d) point to opportunities for further research opened up by this novel understanding.

\section{TIME AND TEMPORALITY IN CONSUMER RESEARCH}

Consumer researchers have studied time and temporality from a number of perspectives, including economics, psychology, sociology, and social psychology (Bergadaà 1990; Hirschman 1987). Studies drawing on economics conceptualize time as a valuable intangible resource that exists in limited and finite quantities. Consumers can use or acquire time by trading another resource, such as money or effort (Feldman and Hornik 1981; Jacoby, Szybillo, and Berning 1976; Leclerc, Schmitt, and Dubé 1995), and it can then be allocated across consumption activities or tasks (Holbrook and Lehman 1981; Kaufman, Lane, and Lindquist 1991; Okada and Hoch 2003).

Psychological accounts stress the implications in consumption experiences of an individual, subjective perception of time (Graham 1981; Hirschman 1987; Hornik 1984; Kellaris and Kent 1992), time orientation (Bergadaà 1990), or "timestyle" (Cotte et al. 2004; Usunier and Valette-Florence 2007). These studies have explored individual consumer differences in judging duration, relationships between time perception, and psychological qualities such as personality or mood (Hornik 1993) but also how marketers can influence time perception, for example, through service environment design (Baker and Cameron 1996; Kellaris and Kent 1992). In addition, consumer researchers have given attention to the consequences of waiting time for service evaluation (Taylor 1994) and product or service purchase decisions (Tsai and Zhao 2011). These studies conceive of time as episodes of a universally constant stream, a physical absolute that individuals merely perceive or judge differently.

In contrast to the economic and psychological views of time, sociological, and social-psychological perspectives contend that time is a social construction based on the socialcultural context in which it is valued (Hirschman 1987) and that consumption lifestyles or collective identities of consumers can influence temporal orientation (Brodowsky, Granitz, and Anderson 2008). This last point of view corresponds with our conviction that social structures and processes shape consumers' uses and perceptions of time, and that inquiry into the socially shaped temporal dimension of consumption may offer important insights for consumer research. In this vein, consumer researchers have been encouraged to examine the role of temporality in directing the consumption process more fully (Arnould and Thompson 2005). While researchers in consumer culture theory have arguably taken important steps toward this end, they have mainly examined distinct, temporal experiences in the context of services (Arnould 2005; Goulding et al. 2009). Others have taken a macrolevel perspective on time frames, addressing the ways consumers use various material, symbolic, and experiential resources to enact their identities and lifestyles in the course of different life cycles, life transitions, and life stages (Arnould and Thompson 2005; Schau, Gilly, and Wolfinbarger 2009).

While agreeing with these basic premises, we extend the notion of time as a social (rather than physical or psychological) dimension toward a microperspective. Unlike prior accounts, we study time "in action" as it unfolds in consumers' experience of concrete, lived-through moments. Further, instead of viewing temporal orientation or timestyle as a feature of the individual (Cotte et al. 2004) or group (Brodowsky et al. 2008), we approach temporality as a feature of consumption practices that individuals engage in. We thus complement prior research that has recognized temporality as playing a significant role in shaping consumption experiences. For instance, temporality and rhythm are defining features of the clubbing experience: "Hours passed in what felt like minutes" (Goulding et al. 2009, 763). Similarly, in the experience of surfing, "the time signature of your surroundings is impossible to ignore. You can be at a place for 72 hours, and it feels as if you've been there for two weeks" (Canniford and Shankar 2013, 1056). Further, participation in a high-risk pastime such as skydiving can momentarily cause one to lose one's sense of time: "[participants] collectively respond that nothing exists in the world but that moment itself - no sense of time, just a kind of holistic oneness that makes them feel good and somehow changed" (Celci et al. 1993, 11). However, while these accounts have identified timeflow as an aspect of consumption practices, they say very little about how such situated, temporal experiences come about and are constituted, what factors influence them, or how they might change over time. To address these gaps in literature, we analyze the different factors influencing experienced temporality in greater detail. 


\section{FROM SERVICESCAPES TO PRACTICES}

The concrete factors determining consumers' temporal experience have been studied most closely in retail and service contexts (Baker and Cameron 1996; Bitner 1992; Durrande-Moreau 1999; Katz et al. 1991; Leclerc et al. 1995). Decades of empirical studies of waiting have established that consumers do not experience time as the perfectly homogenous continuum of cosmic time (Maister 1985; Taylor 1994). Consumers systematically overestimate waiting time in retail checkout lines (Hornik 1984), because "unoccupied time feels longer than occupied time" (Maister 1985, 115). An array of factors can lead to "negative waits," including anxiety, anger, uncertainty, punctuality, unoccupied time, lack of communication, or unfair treatment. Accordingly, many researchers have shifted their focus from influences on the absolute time spent waiting, such as managerial actions that speed up services (Hui, Thakor, and Gill 1998; Taylor 1994), to exploring factors that influence consumers' experience of waiting time. These aspects include customer entertainment (Katz et al. 1991), service convenience (Berry, Seiders, and Grewal 2002), mental wait-management strategies (Miller, Kahn, and Luce 2008), information about the length of or reasons for waiting (Hui and Tse 1996; Hui, Tse, and Zhou 2006), or various aspects of physical and atmospheric design (Baker and Cameron 1996; Bitner 1992). For example, olfactory cues such as a pleasurable scent (Spangenberg, Crowley, and Henderson 1996) or background music (Hui, Dubé, and Chebat 1997; Knoferle et al. 2012; Milliman 1982, 1986; Oakes 2003) can enhance shoppers' subjective experiences, increase lingering time in stores, and reduce the perception of waiting time.

While notable for their consistent findings and immediate managerial relevance, however, prior studies do not consider cross-modal correspondences and cross-influences between the senses, nor the full range of material, bodily, and social influences shaping consumers' experience of time. As Ezeh and Harris $(2007,70)$ point out in their comprehensive literature review, "only very few studies have incorporated more than one servicescape element." We suggest it is time for moving from empirical research on isolated, contextual variables toward building a holistic understanding of experienced temporality as occasioned or keyed by the overall situational embedding of a consumption activity. We also argue that prior research has remained unnecessarily restricted to service contexts. To study temporal experience, we therefore shift from servicescapes to practices as an enabling concept. As we show next, in doing so we extend -rather than reject-core notions and findings from both interpretative (Sherry 1998) and experimental (Ezeh and Harris 2007) studies of the servicescape.

Importantly, a servicescape is not only a "physical container" (Bitner 1992) within which consumption happens, but "a subset of social rules, conventions, and expectations in force in a given behavior setting, serving to define the nature of social interaction" (Bitner 1992, 61) - and inter alia, its temporal nature. This definition, informed by environmental psychology (Darley and Gilbert 1985), comes close to contemporary practice theory's conviction that rules, routinized doings, and shared understandings organize and define the situated performances of social practices (Schatzki 1997). Bitner's (1992, 65) emphasis that the perceived environment manifests in the form of "a holistic pattern of interdependent stimuli," or "the total configuration" of consumer emotions, moods, interaction patterns, and plans is matched by practice theory's conception of social practices as bundles of different elements (e.g., the material, spatial, social, and symbolic) being woven together in any concrete moment of performance. Significantly, this overlap not only concerns the elements identified as influential, but extends to how these elements relate to perception and action.

Notably, the purpose of Bitner's theoretical framework is not to explain how actions are caused but rather how experiences are conditioned, as the "perceived servicescape does not directly cause people to behave in certain ways" but instead shapes conditional variables of consumer behavior, such as emotions, moods, social interaction patterns, plans, or tasks (Bitner 1992, 62, emphasis in original). This conceptualization mirrors practice theory's insistence that "understanding et al. are not states of an abstract mental or real underlying apparatus that are causally related to actions. They are, instead, conditions of human existence: aspects of how things stand or are going for someone ongoingly involved with persons, objects, and situations" (Schatzki 1997, 303).

Temporality is thus difficult to address with theories that take mental processes or subjective agency as their basal unit of analysis. Only in certain situations is time the full focus of attention, decision, or social expression. Yet time is concurrent with all our doings not only from a (meta)physical point of view (Heidegger 1962). It is also always on the horizon of our experience as a part of the background of activities (Merleau-Ponty 1962; Schatzki 2010), against which notable experiences like great service, deep satisfaction, or unnerving waiting stand out. If we are to grasp consumers' temporal experience theoretically, it is precisely this background of activities we must pursue. Accordingly, analysis of temporal experiences should not be mapped onto personal or psychological traits but instead onto the situational embedding that creates perceptions of temporality through a multifaceted mesh of the elements of a practice (Arsel and Bean 2013; Shove et al. 2012).

We therefore extend the notion that "servicescapes afford consumers different holistic, embodied temporal experiences" (Arnould 2005, 93) into a more general and more flexible framework. We assert that the performance of consumption practices occasions experienced temporality in consumers. While a number of works arguing from a practice perspective have pointed out the importance of routines and social rhythms, spatiality, body, and materiality for shaping the temporal structures of everyday life (Jalas 2006; Laurier 2008; Shove et al. 2009; Southerton 2006; Toyoki et al. 2013), none of these studies has directly examined the concrete experiences of temporality that accompany the con- 
duct of a particular practice. In doing just that, we build on Schatzki's $(2009,2010)$ recent philosophical account of the nature of time that follows the tradition of Heidegger (1962). In addition to the continuous flow of objective time of the general physical world, Schatzki argues, the performance of practices opens up "activity timespaces": distinct episodes of temporality characteristic of the activity in question. While we have drawn inspiration from this line of thought, our theoretical approach differs in that we conceptualize the structure and origin of consumers' experiences of temporality (the timeflow of practices) rather than the ontological nature of time per se (timespaces).

\section{THE TIMEFLOW OF CONSUMPTION PRACTICES}

We define timeflow as a quality of (consumption) practices. Different practices can have different timeflows that vary in speed, rhythm, and tempo. Compare, for example, the temporal flow of skydiving to that of yoga or the repetitive intervals of tennis. Timeflow describes the temporal interrelation (or hanging together) of meaningful events that happen in the course of the ongoing normal conduct of a practice. Practitioners experience the unfolding of meaning in a timeflow typical for performing that practice. For example, the experience of freeskiing resembles that of riding a roller coaster in that it exhibits a very specific temporal flow that entails both episodes flashing by in an instant and intensive moments where time stands almost still. In other words, while the temporal unfolding of events never fully ceases, it changes speeds and rhythms, or escalates or deescalates. Although every concrete event can be said to happen within a universal or cosmic stream of time (the general temporal concurrence of physical events), our notion of timeflow refers to the unfolding of meaning in conduct of a practice as a general quality of that practice. The timeflow of a consumption practice is not the same as the durée (Bergson 1911) or inner time perception that traditional phenomenology is concerned with (Husserl 1991). In our framework, timeflow is a quality for the practitioner (a consumer engaged in the practice) but of the practice.

Since this notion forms the very core of our argument, we explicate it in greater detail. First, our definition refers to meaningful events, not physical or ontological events per se. Skiing down a steep slope, for example, could be considered to be a single (ontological) event or a series of many separate events. The timeflow of a practice is therefore not actually a physical dimension, even though a practitioner would sometimes experience or describe it as such. For example, cosmic time does not stand still, in spite of skiers' perception for an instant as they hang weightlessly in the air. This decoupling of timeflow and cosmic time results from defining timeflow as a quality of the unfolding of meaning: not every physical event makes a difference in terms of meaning.

Second, if we link timeflow to the unfolding of meaning, we must specify for whom this meaning supposedly exists.
Critically, from a practice perspective meaning is treated as occurring exclusively within the course of conducting some social practice. An object like a ski, for example, is not inherently meaningful but must be put into practice in order to make a difference. More precisely, we hold that the timeflow of a practice is-in the words of Merleau-Ponty (1962) - a quality of the phenomenal field of the practice (Garfinkel 2002). Timeflow is, so to speak, a feature of the face that the practice turns toward the practitioners. The phenomenal field of skiing consists of proprioceptions of sharp acceleration, abruptly changing orientations of the body, wind in the face, changing vistas of the surrounding landscape, different sounds, and so on. The timeflow of the practice producing this particular phenomenal field then describes a quality of the sequential ordering of these typical elements: the pattern of their succession such as the speed, acceleration, or repetitions.

Importantly, building on the concept of social practices does not remove the perceiving human from the equation. Timeflow is defined as a quality for a practitioner (a person engaged in a practice). It can be perceived in this particular way only for a practitioner of that particular practice in the ongoing course of its conduct. For example, a worker supervising the safe operations of the snow park in which the freeskiers train will experience temporality very differently, since it most probably becomes part of a boring, repetitive routine. This difference is not surprising, since the worker conducts a different practice composed of different bodily doings, governed by different implicit social norms, and oriented toward different ends.

To explore the nature of timeflow and our hypothesis about the relationship between elements of a practice and the temporal experience its performance evokes, we now introduce the empirical cases and methods we used to systematically investigate the influence of different elements on practitioners' temporal experience, paying special attention to situations in which practice elements were misaligned and the effects of this misalignment on temporal experiences.

\section{METHODS AND DATA: ETHNOGRAPHIES OF TEMPORALITY}

Next, we move from examples to concrete empirical cases that provide a more nuanced understanding of the nature of timeflow. We chose extreme or lifestyle sports as our empirical context because these practices offer extreme temporal experiences, such as rush and rapid accelerations, but also moments where time seems to stand still, or where patient waiting is necessary (Canniford and Shankar 2013; Celci et al. 1993). While temporal features of mundane and highly routinized practices can be hard to detect or explicate, the extreme nature of the practices allowed us better access to this tacit dimension of consumer experiences. Lifestyle sports also provide a multitude of subcultural media that - unlike many other mundane consumption practices - can be readily accessed and used in documentation and analysis. 
To this end we conducted multiyear, multisited ethnographies of temporality in two sports. First, we studied paintball (see fig. 1), a competitive lifestyle team sport notable for its engaging, adrenalin-drenched game play characterized by a rapid development of events. Second, we studied freeskiing (see fig. 2), which is a highly demanding and styledriven solo performative sport (and Olympic discipline).

We conducted a comparative case analysis to discern similarities and differences in the context-specific temporal experiences and to develop our key theoretical themes with coherence and consistency. To this end we carried out ethnographic fieldwork in five countries during 2008-2013 to uncover the timeflow in freeskiing and paintball (see table 1). Since the experience of temporality has its roots in several sensory modalities, we combined various methods that can be used for phenomenological inquiries, namely participant observation, photo, video and audio recording in natural settings, and interviews (Canniford and Shankar 2013; Gobo 2013; Joy and Sherry 2003; Valtonen, Markuksela, and Moisander 2010).

Our entire data set consisted of participant observations in 16 field-site locations, 1,230 photos and 61 hours of video footage, 60 recorded interviews with participants and industry professionals, over 180 informal interviews, 74 volumes of special-interest magazines (from 1999 to 2012) and subcultural media content, including 25 DVDs and over 300 participant-made videos streamed online. As our research goal was to gain an in-depth understanding of the timeflow of the two consumption practices, we interviewed participants from diverse backgrounds, from different countries, and in particular from various levels of expertise. International and local training and competition events, ranging from single-day to week-long sessions, were the principal way to recruit participants using purposive sampling through personal contacts.

Driven by our practice-theoretical perspective, the analytical procedure we followed aimed at producing comprehensive accounts of timeflow. We achieved this by collecting insights about the temporal details of practitioners' experiences as they unfold in concrete, lived-through moments of performance. We then aggregated these insights to reach beyond the local contingencies of here-and-now practice performances (Reckwitz 2002a; Warde 2005) to identify the general and stable features of the timeflow of a practice. Sensitized by our theoretical framework, we were attentive to the events, discourses, and observations suggesting that the timeflow of a practice became more or less smooth or aligned for the practitioners, but we also noted how such instances showed up in our data or were expressed by practitioners. The triangulation procedure employed not only comprised the use of multiple methods within a given research project (Arnould and Thompson 2005; Epp and Price 2010) but functioned principally as a way of "combining different sorts of data against the background of the theoretical perspectives" (Flick 2008, 41) to ensure quality (Seale 1999). We iteratively contrasted researcher field

\section{FIGURE 1}

\section{PAINTBALL}

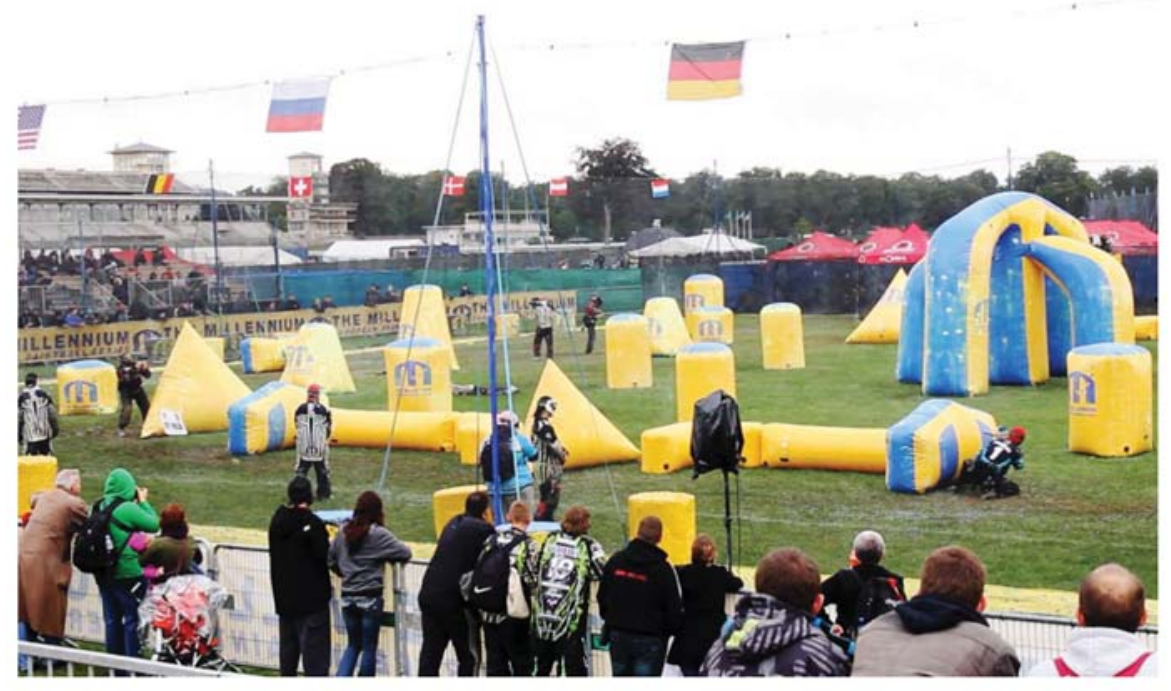

NOTE.- International paintball tournaments feature a continuous stream of games from preliminary rounds to the finals over a weekend. Much of the time is spent waiting for the next game. 


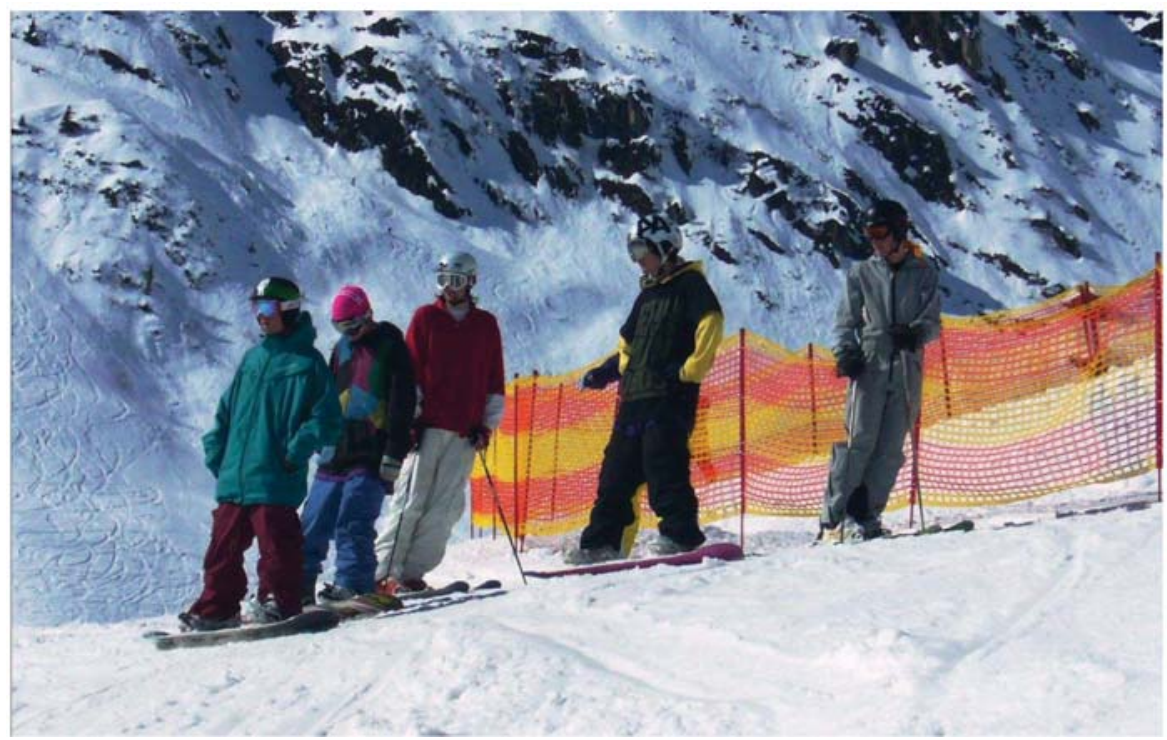

NOTE.-Freeskiers and snowboarders lining up atop a kicker in a snowpark. They do not visibly interact or otherwise pass the time but instead watch the kicker below intently. A considerable part of a typical day of freeskiing is spent in this way.

notes, first with video-aided observations of the daily routines of players and skiers, second with accounts from phenomenological interviews, and third with the discursive notions and video scenes circulating in the subcultural media. After carving out the general temporal structures manifest across performances of one practice involving different participants in various locations, we then compared different versions of the same practices, for example, paintball matches that follow two distinct sets of rules. In the last step we checked the effects one element had in a certain practice against its effect in a different practice.

\section{FINDINGS: THE NATURE OF TIMEFLOW}

In this part, we show how consumers' experience of time is occasioned by their participation in the performance of a consumption practice. Instead of seeking to isolate singular factors as having an impact, we develop a holistic account of the total configuration of interdependent influence factors that condition consumers' temporal experience while performing a practice. We conceptualize these factors as elements of consumption practices that collectively shape the timeflow of the practice, and we subsequently show that a misalignment of elements induces an experience of temporal drag or temporal rush. Our findings also reveal that different versions of practices may have distinctive timeflows.

\section{Timeflow as a Holistic, Situational, and Embodied} Temporal Experience

The following field note illustrates how participants may experience a typical paintball game. Although failing to transmit much of the visceral excitement playing entails, a video link from our data offers more details of the highly visual nature of a similar paintball experience: http:// www.youtube.com/watch?v = mbdlBQNfU44.

Hiding behind the bunker on my knees and trying to press my chest as close to the bunker as possible. Hearing the opponent's shots hitting the bunker's left side, about $20 \mathrm{~cm}$ away from my mask, splashing small drops of paint on the ground. I feel like I've been waiting in this awkward position for a short eternity, although I just sprinted here and I am still trying to catch my breath. My knees hurt and my paintball marker, which weighs at least 5 kilos, is not easy to hold up steadily so I am resting a few seconds. There's a sudden break in the otherwise continuous fire bouncing off my inflatable hideout bunker. I make a quick move to the righthand side to see if I can open fire across the field toward my opponent. Although I try to do it in a split second, it seems to take forever and I feel like I can't fully control my moves. Where is the guy now? I cannot see anything. I break the abrupt silence by firing an uncontrolled stream of shots toward the right corner bunker. My heart pounds and I lose my breath as my body is exposed to the opposing players for a moment. Should I run to the next bunker? Too late, I can 
TABLE 1

SUMMARY OF DATA COLLECTION ACROSS EMPIRICAL CASES

\begin{tabular}{|c|c|c|c|c|}
\hline & Interviews & Participant observation & Photos, video & Subcultural media \\
\hline Freeskiing & $\begin{array}{l}12 \text { athletes and } 21 \text { indus- } \\
\text { try professionals, } 80 \text { in- } \\
\text { formal interviews }\end{array}$ & $\begin{array}{l}11 \text { outdoor snow parks in } \\
\text { Germany ( } 2 \text { in Bavaria), } \\
\text { Austria (5 in Tirol), and } \\
\text { Switzerland ( } 2 \text { in Grau- } \\
\text { bünden, } 2 \text { in Wallis), } 1 \\
\text { indoor snow park } \\
\text { (Germany) }\end{array}$ & $\begin{array}{l}650 \text { photos; } 9.5 \text { hours of } \\
\text { video footage }\end{array}$ & $\begin{array}{l}44 \text { issues of freeskiing } \\
\text { magazines (2006- } \\
2012), 25 \text { freeskiing } \\
\text { DVDs, over } 200 \text { partici- } \\
\text { pant-generated videos }\end{array}$ \\
\hline Paintball & $\begin{array}{l}21 \text { players and } 6 \text { industry } \\
\text { professionals, over } 100 \\
\text { informal interviews }\end{array}$ & $\begin{array}{l}5 \text { paintball sites in Finland } \\
\text { (Turku, Hyvinkää) and } \\
\text { France ( } 2 \text { in Paris, } \\
\text { Toulouse) }\end{array}$ & $\begin{array}{l}580 \text { photos, } 52 \text { hours of } \\
\text { video footage }\end{array}$ & $\begin{array}{l}30 \text { paintball magazines } \\
\text { (1999-2012), more than } \\
100 \text { participant-gener- } \\
\text { ated videos }\end{array}$ \\
\hline Total & $\begin{array}{l}60 \text { recorded formal and } \\
\text { over } 180 \text { informal } \\
\text { interviews }\end{array}$ & $\begin{array}{l}\text { Participant observation in } \\
16 \text { different field-site } \\
\text { locations }\end{array}$ & $\begin{array}{c}1,230 \text { photos, over } 61 \\
\text { hours of researcher- } \\
\text { made video footage }\end{array}$ & $\begin{array}{l}74 \text { special interest maga- } \\
\text { zines, } 25 \text { DVDs, over } \\
300 \text { participant-gener- } \\
\text { ated videos }\end{array}$ \\
\hline
\end{tabular}

feel stingy bites on my left shoulder. Orange paint everywhere. I'm out. I'm hit. I can't breathe. I can taste some paint in my mouth. (Field notes from training session, Hyvinkää, Finland).

The paintball player on the battlefield registers the fastpaced temporal flow on a number of different yet related levels: feeling the pace of his heartbeat, hearing the ambient sounds of the fighting, sequences of running and hiding, shooting going on around him, attuning to the visible excitement of his teammates or opponents, and so forth. The felt aspects of temporality, in other words, depend on the particular sensory "scape" or phenomenal field a certain situated conduct evokes. In a typical game of paintball this phenomenal field is hectic, as five players from two opposing teams enter the field composed of inflatable bunker hideouts with the purpose of eliminating their opponents by shooting them with paintball guns. In this conduct, the players live through repetitive sequences of compressed action requiring them to be constantly alert and focused in order to manage the danger of being hit. Yet according to our participants, this imminent stressfulness is not considered a negative aspect of the game. As Nathan, an amateur paintball player explains, the hectic feeling is exactly what seems to create the excitement and thrill of the sport:

Nathan: It feels really good. It's an adrenalin-pumping game. It's crazy, it's a whole other feeling. You don't understand it if you don't go on the field.

Interviewer: Where does the adrenalin come from then?

Nathan: As soon as the buzzer starts and you are heading off the field, it just comes naturally. It's just a blood-pumping game. Rapid sport.

\section{Interviewer: Rapid?}

Nathan: It comes from the heavy pressure being put on you by the opponents obviously. They want to shoot you. (Nathan, amateur, 3 years of experience, UK)
The participants in paintball refer systematically to the "speed," "rapidness," or "fastness" as an important quality of the sport and its appeal:

I love the strategy and tactics you need in this game. And also the fastness. Of course you have to be athletic too, and there is the team feeling. (Andrea, amateur, 4 years of experience, Switzerland)

Phenomenologists have argued that the phenomenal field that enwraps subjects during certain activities such as scuba diving (Merchant 2011) or crossing a large terminal (Frers 2007) evokes a "tuned" experience of the body and the world, for example, that of floating weightlessly in the ocean or being immersed in the buzzing atmosphere of a terminal hall. One aspect of such embodied attunement is the specific temporality of the situation (Merleau-Ponty 1962), such as the "timelessness" of floating or the "busyness" of striding toward the closing flight gate. We hold that the rush of the paintball match should be understood in a similar manner. Importantly, paintball's timeflow is not so much a matter of interpretation as one of exposure. Every player we spoke to, whether novice or expert, had felt the adrenaline-saturated surge of the game, much like passengers on a roller coaster almost inevitably feel some intensive rush. Although paintball players might react differently to this rush or, to some, extent become accustomed to it over time, no informant seemed to fully escape these bodily feelings and frenzied thoughts:

If you start to play paintball you are always hectic, because you're nervous. But in this sport you have to learn over the years that when you are in the bunker, you have to keep cool. And in a way not to be hectic. What makes it hectic is of course the bullets that you are facing. (Andrea, amateur, 4 years of experience, Switzerland)

We therefore argue that experienced temporality is not the result of purely inner-subjective or cognitive interpre- 
tative work on behalf of practitioners. Rather, it is intrinsically enmeshed in running, ducking, shooting, attacking, and trying to stay in the game. Accordingly, we hold that temporal experiences should not be mapped onto personal or psychological traits but instead onto said activities or practices.

\section{Five Practice Elements That Shape Timeflow}

One might conclude that experienced temporality should be considered an immediate effect of material artifacts and technology. However, we do not suggest that, taken in isolation, the material set-up of the paintball game evokes a particular timeflow. In contrast to players, referees walk upright between the bunkers and the buzzing bullets. They experience a different timeflow brought about by heightened concentration and swift decision making but not the visceral excitement of playing itself. Since paintball participants frequently switch between the roles of player and referee, this different experience does not result from dissimilar individual traits or cultural backgrounds among players or referees but from the fact that each is engaged in a different practice.

At the heart of our conceptualization of timeflow as a quality of consumption practices (rather than individuals, objects, or the world at large) is the observation that temporal experience does not depend on isolated influence factors, but rather on the way the divergent elements that make up a situational embedding hang together, or fit in. Comparing the role of music in freeskiing to the approach taken in prior studies on background music in stores (Hui et al. 1997; Knoferle et al. 2012; Oakes 2003) clarifies this point. Throughout a day of training, freeskiers listen to music almost constantly. All informants considered listening to the right tunes to be an important element of a successful training run. Music helps them to be motivated, stay focused, and "catch the flow" required for an elegant and expressive performance on skis. However, for this effect to take hold, they must find the type of music (and often even the artist and song) that matches the challenge at hand. Sarah describes the prerequisites for performing a highly dangerous trick on a large kicker:

I need my music, that is really important, so that I can find my groove. . . . If I am at a large kicker where I need to go at it with full speed, for example, then I like to listen to aggressive punk rock. . . That really pushes you, and then I go for it. (Sarah, amateur, 7 years of experience, Germany)

Importantly, Sarah does not simply describe a favorite type of music. Instead, she describes a carefully curated constellation of matching elements of the situation. The physical layout of the large kicker (the material set-up), the bodily performance of going at full speed (her bodily routines and skills), the type of trick she intends to undertake and the go-for-it attitude it requires (the interlinked teleological and affective structure of her performance), as well as her cultural understanding of what comprises an aggressive, challenging trick all align neatly with the specific genre (and volume) of music she needs to listen to. Collectively, they produce what she calls her "groove"-a particular timeflow befitting the kind of performance she undertakes. In practice theory, these key elements of the situation are understood to be the elements of the practice currently being performed. The accomplishment of a practice performance requires a suitable organization of these elements (Shove et al. 2012).

The idea that social practices are organized bundles of entangled elements is at the heart of practice thought. Its implication is that when performing a practice, we never encounter an element in isolation, as the element is always already bound up in a local context framed by a material set-up, some bodily activity we are currently pursuing, emotional states and moods we are in, the social rules and norms currently in play, and the cultural understandings that apply. Drawing boundaries between discrete elements is accordingly a matter of adequate theoretical definition rather than ontological givenness. For this reason, authors identify slightly different sets of elements (Reckwitz 2002a; Schatzki 2002). For example, a number of authors have used a threefold model that distinguishes objects, doings, and meanings (Arsel and Bean 2013; Magaudda 2011). While this model worked well in these cases, it was explicitly introduced as a "reductive scheme" and "simplifying move" by Shove and colleagues (Shove and Pantzar 2005; Shove et al. 2012, 15, 23) for the purpose of studying how practices relate on a macro scale. In zooming in on the effects of a particular practice, they note (Shove et al. 2012, 113), a different vocabulary might be more useful.

For our purpose of tracing the formation of timeflow, we found that the category "meaning" should be split into the three categories: rules, teleoaffective structures, and general cultural understandings (as suggested by Schatzki 2002). We also speak of "material set-up" instead of "objects," and "bodily routines and skill" instead of "doings" to emphasize that both-like all elements of a practice-structure practical conduct in a particular way. As Sarah's quote exemplifies, the structure of practice performances is not the result of an accidental regularity, but rather the effect of elements that have an organizing effect (Schatzki 2002; Warde 2013, 12). Much like pieces of a puzzle, the elements that are put into practice structure performances as they afford only certain organizations of conduct, and preclude others.

Next, we will accordingly show that all five elements of a practice can influence the timeflow, as illustrated in figure 3. During a performance all elements of a practice can align smoothly, but this is not always the case. Sometimes, an element does not really fit well with the overall constellation of current conduct, such as when a practitioner lacks the bodily skills to handle the equipment used. The effect an element has on the timeflow becomes particularly conspicuous in such situations, and therefore in our discussion of each element we pay special attention to situations of misalignment.

Material Set-Up. The first element of consumption practices that influences their timeflow is the material set-up of 


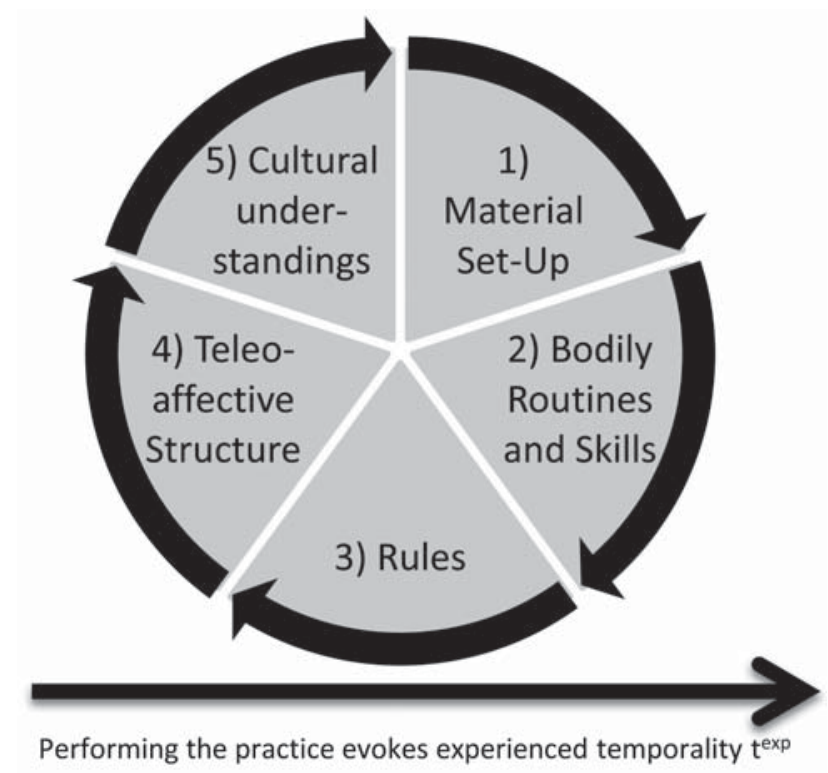

the practice. On the one hand, set-up includes the equipment involved, such as the design of the paintball markers, whose firing rate has a direct effect on the intensity and speed of the game, but also has improved considerably as paintball has evolved from a niche hobby into a professionalized sport.

I think this is a whole new sport today. Back then, we played in the forest, we had very different equipment and guns. They were a lot slower and we shot less balls. (Rami, semipro, $15+$ years of experience, Finland)

On the other hand, this element includes the spatial and material set-up used to perform the practice. While most physical products offered to consumers fall into this category, the relevance of product features for temporal experience has not yet been recognized in the literature, although its relevance has been well documented in the servicescape literature (Bitner 1990, 1992). In freeskiing, for instance, practitioners have learned to build and use ever larger kickers, which provide for longer jumps and thus more airtime. In a testament to the importance of timeflow, freeskiers routinely make comments such as "[This kicker] really gives you crazy airtime!" (Pete, amateur, 15 years of experience, Germany)

Acknowledgment and accounting for the role of technology and spatiality for social order (but without overemphasizing it or disconnecting it from other aspects such as social roles or emotions) is widely considered one of the key accomplishments of contemporary practice theory (Reckwitz 2002a, 2002b; Schatzki 2002). In line with prior research (Epp and Price 2010; Truninger 2011), we hold that material objects are deeply entangled with the other elements of social practices in that they configure and constrain the local performance of practices. Said entanglement is not always without problems, since a lack of fit between, for example, the material and bodily elements has an effect on timeflow:

With this [new ski] I first went skiing in [a small resort] for a day. I had to start a bit slower until I realized that it is ok. But once I have also tried a different ski, where I could do a Switch 360 right away. (Jo, amateur, 8 years of experience, Germany)

The different temporal effects of the two pairs of skis are not directly the result of innate qualities of either ski. Rather, the first pair slowed down Jo's performance as long as the interplay between the ski and the bodily routines of skiing was not yet fully balanced. Just as walking in heavy boots or high heels for the first time creates an uneven flow of walking, a new element that is put into practice requires the skier's body to adapt to its particularities. While much of this adaptation happens under the radar of conscious activity, we argue that one way practitioners notice such ongoing realignment of material elements is through modulation in the temporal experience.

Bodily Routines and Skills. The second element that can have a strong formative effect on the timeflow of consumption practices is bodily routines and skills. The growth and professionalization of both freeskiing and paintball have meant that practitioner bodies have become ever more able, well trained, resilient, and especially fast-moving. More ath- 
letic competitors in paintball, for example, now play a game so fast and demanding that families and recreational practitioners increasingly find themselves excluded. As a team organizer bluntly remarked, "No-one is carrying any weak players." As with material elements, however, if and how bodily skills coconstitute a practice's timeflow and thus affect temporal experience depends on the interplay with other elements. Freeskiers, for example, not only train their bodies to jump farther and spin faster but also use their temporal experience as an indicator of how well the different aspects of their performance have become integrated.

If I am doing a 540 [trick] and I still have a lot of time before landing, then I know right away: "Ok, now I can [advance to a more difficult trick and] add half a rotation more." (Tom, semipro, 14 years of experience, Germany)

Critically, "a lot of time" is an emic description, as the episode this expression describes last less than a second when measured in absolute time. Temporal elongation is an effect of the necessary bodily routines being well trained and smoothly integrated with the demands of the chosen trick, the size of the kicker, the weight of the skis, and so on. To use Schön's $(1983,62)$ expression, a practitioner experiences his conduct as happening in the action-present, "the zone of time in which action can still make a difference to the situation." To the extent that one's physical ability to perceive and react to the fine details of events is variable, temporal structures of experienced activity are modulated by bodily skill. The ability to see in "the right way," for example, can make a key difference on the paintball field:

When you see paint coming at you or away from you, it looks very close together. This is not the case. If you could somehow stop time, and break out a measuring tape, you could see there is a gap between each ball in space as you shoot. . . . And there's more than enough time to go through [the line of fire]. (Jake, pro, 15+ years of experience, United States)

The fundamental role of physical routines for the temporality of consumer behavior is reflected in practice theory in that bodily doings are commonly considered the irreplaceable core element of all social practices, regardless of whether they are called bodily routines (Reckwitz 2002a; Schau, Muñiz, and Arnould 2009; Warde 2005), embodied skills (Shove et al. 2012; Truninger 2011), or bodily doings (Schatzki 2002). Our conceptualization of experienced temporality as rooted in embodied experience affected by the bundle of practice elements reflects this notion. Preconscious bodily routines such as having a heartbeat or breathing are directly intertwined with the timeflow of the practice that is currently being performed, because they are strongly affected by the performance and in turn coshape what practitioners do and how they experience it. One of the most gripping temporal experiences, for example, befalls us when we have to hold our breath. We further observe that misalignments between practice elements often concur with tense temporal experiences. The fact that "you're trying to stay alive" (James, Pro, 14 years, United States) on the paintball field drives up a player's heart rate and creates a feeling of being under pressure, and the freeskiers' fear of hurting themselves owing to a lack of skill invokes shorter and quicker breaths and a feeling of events approaching faster than they would like. We thus argue that "optimal" temporal experiences (Csikszentmihalyi 1990), such as forgetting time in yoga, are due to the perfect alignment between bodily routines, the situational setting, and the teleological or affective state that is being achieved during performance.

Teleoaffective Structures. As our empirical vignettes of freeskiing and paintball have shown, practitioners focus intensely on a specific goal immediately ahead of them: performing a particular trick or taking out an opponent. Importantly, this goal-directedness is not only a state of mind but goes hand in hand with a bodily tension (e.g., being ready to fire at any moment) and a sensory perception fully focused on a narrow range of details (e.g., keeping a sharp eye on the kicker while ignoring all bystanders).

The term "teleoaffective structures" was introduced by Schatzki (2002) to describe the fact that the bodily doings that compose a practice are not only linked by explicable social rules and understandings but also by implicit mental conditions such as ends and emotions, in light of which practical activities are undertaken. Teleoaffective structure is the third factor that influences the timeflow of a practice. Adequately explaining experienced temporality in light of the strong effects of momentary intentions and affections we found at work in the practices we examined requires treating ends and goals as part of the practice bundle-that is, as implicated by the type of current conduct one engages in, rather than by individual cognitive states or psychological traits. In paintball, the predominant end-not to be hitseems almost palpable once one steps onto the field and comes under fire. This goal deeply permeates all perceptions and activity, imbuing them with a sense of vulnerability and urgency essential to the game's action-packed temporality. This end, in other words, comes almost naturally with the activity, and it would be mischaracterized if treated as a subjective decision somehow external to the game.

One particular type of teleoaffective structure that has been shown to influence temporal experience is consumers' mental coping strategies for stress during waiting. This strategy is the so-called wait management, which consists in orienting oneself toward different types of goals (Miller et al. 2008). We propose that our framework can help study similar effects with regard to many more practices beyond waiting. For example, freestyle skiing entails certain ends (and connected emotions) particular to this social practice. Indeed, the sport is defined as skiing for the sake of reproducing a certain style. In other words, the practitioners' conduct is organized toward the end of looking stylish, and only because this is the case are they emotional about the failures and successes that occur during that endeavor. As the following quote illustrates, it is this teleoaffective structure that lends a sense of fatefulness and tension to the brief 
moments of attempting a trick that constitutes the tense temporal experience of the athletes:

I don't think it is as calm as in a normal situation. . . . Although I have more than one attempt, I really want the first one to work right away. . . . You are definitely more under pressure. (Tom, semipro, 14 years of experience, Germany)

Importantly, unlike some models of goal-driven action, a practice perspective assumes that several possibly antagonistic ends and emotions might be at play concurrently. Simultaneously with their teleological orientation, practitioners of freeskiing experience viscerally felt emotions that often run directly counter to the immediate ends, especially in that they fear crashing and hurting themselves.

The slower I am, the less airtime I get; and when I am too slow, it hurts really badly when I crash. . . . And the main problem is that fear slows you down. . . . You break just before the kicker although you did not want to. . . . That is a vicious circle [in that the fear of crashing causes the crash]. (Tom, semipro, 14 years of experience, Germany)

Similarly, in paintball the teleoaffective structure is linked with commitment to the team, making the players manage or escape the hectic thoughts on the field:

It requires thinking, a "mind-set," you know. You have to know where the shooting lines are, where the opponents are, where your own guys are. Then you can keep cool. (Andrea, amateur, 4 years of experience, Switzerland)

At the right moments you also have to be fast and move forward. And do something for the team. (Jessica, amateur, 5 years of experience, Switzerland)

We suggest that the unusually intense timeflow that characterizes both of the so-called extreme sports we examined stems from their elements becoming easily misaligned, for example, when antagonistic teleoaffectivities are at play. In freeskiing, the fear of crashing is due to a possible mismatch between the material set-up (the kicker might be too small or the snow too slow) and the demands of the attempted trick. This fear then wrestles with the deep-felt urge to finally master a stylish trick. Because freeskiers continuously seek to push their boundaries, their conduct is almost always fragile and characterized by small misalignments between different practice elements. We argue that such misalignments create both the temporal rush of freeskiing as well as situations where time seems to stand still, as in the opening field note. Likewise, the pressure and rush of paintball emanates from a tension between a thrilling sense of exposure and an intense drive to attack - a tension that in turn shapes the particular timeflow of the practice. Together, fear and desire for mastery coproduce the temporal crescendo or rush characterizing each move, as well as the euphoria experienced upon success, a feeling in turn responsible for the addictive nature of these sports despite the seemingly long periods of waiting they entail.

Rules. The dramatic acceleration of the paintball game format over the years is largely due to games today ending not only with the elimination of the penultimate player (something that might only happen after a full day of playing) but alternatively after ten minutes on the game clock. The formalized temporal framing of a practice, in other words, clearly influences its timeflow. Such explicit and formal regulations are only the most obvious form of a range of related phenomena, such as rules of thumb, strategies, tactics, heuristics, recipes, instructions, or mundane sayings that organize the conduct of consumption practices. We summarize them under the umbrella term "rules" and find that they shape the timeflow of practical conduct. For example, according to paintball players, actions during the pivotal first moments of each new game point - the so-called breakare governed by the rule of thumb "How far can you sprint in 3 seconds?" A similar basic strategy is the division between "attackers" rushing toward the opponent and "back players," who stay at the rear of the field and focus on shooting rather than running. This separation of tasks induces quite different experiences of temporality between those calmly waiting for an opponent to appear in their line of fire versus those frantically struggling to dodge paintballs as they leap from bunker to bunker. Together with the strategic script players agreed upon earlier, this division structures the overall temporal flow of the game. For example, coordinated action escalates at a particular moment, such as an early rush, or slows down considerably when only a few back players are left standing.

In some cases, the effect of rules on timeflow is quite direct and obvious. For example, formally limiting the number of permissible rotations in a freestyle trick implies slower rotations, and paintball's basic rule that a single hit immediately eliminates a player adds much to the game's intensity and speed. In the case of waiting in a store, implicit rules of civility prescribe how long a customer has to wait until her or his proper turn comes about. In other cases, rules take the form of explicit laws, norms, standards, or recipes. Rules differ from cultural understandings in that they are explicit formulations designed to orient a certain activity, whereas cultural understandings such as those of taste or beauty are tacit, nonprescriptive, and much more widely applicable (Schatzki 2002). Freeskiers distinguish between a performance that is merely technically correct (e.g., a 1080 consists of three full rotations) and a performance that is stylish. While judges can refer to their rulebook to determine whether a trick has been correctly executed technically, they must rely on their acquired sense of subcultural style to evaluate the trick's "looks."

In practice-minded consumer research, rules have not yet received much attention and are not usually considered to be separate elements of consumption practices. However, we draw attention to the fact that rules are described as a core part of social practices (Reckwitz 2002b; Schatzki 2002) and that discussions of the importance and nature of rule-following have been at the root of the practice turn in the social sciences since Wittgenstein's foundational remarks on the topic (Bloor 2001; Stern 2002). In addition to 
our empirical observation that rules co-structure timeflows, we find a solid theoretical basis for our argument that rules are distinct and relevant elements of practices that influence timeflow.

Cultural Understandings. The fifth and final dimension of factors that structure timeflows is formed by the discourses, cultural tropes, or value systems that play a role in the social organization of practices. We summarize these under the term general cultural understandings. Examples include the team spirit of paintball crews, concerns for athlete safety, ethical arguments, or considerations of the audience attractiveness and marketability of the sport-all of which have resulted in modifications of the temporal flow of the practice.

Consumption practices like freeskiing and paintball are embedded into frameworks of cultural understandings, such that the performance of practice is seen as an expression of a certain understanding, as for example that performing freeskiing demonstrates creativity and individuality, or winning a tough paintball match proves valor and strength of will. However, only some practice performances can be seen as an adequate expression of a certain cultural understanding (e.g., they are many ways of talking, only some of which are polite). In freeskiing, athletes seek to express a certain understanding of style through their performances, and disagreements prevail over which formats of skiing are adequately express such style:

In many free ride contests, they measure the time [needed for a descent] to find the best rider. They don't look at elegance or radicalism at all [but instead let the fastest rider win]. And that is why some of the best riders are not competing in contests. Because they cannot stand that. (Tom, semipro, 14 years of experience, Germany)

Practitioners monitor a performance's adequacy in expressing a certain understanding, and in this way, general understandings guide the organization of practices (Schatzki 2002). Arsel and Bean (2013), for example, show how the everyday practices of home making have come to be organized according to aesthetic ideas of "soft modernity," and Truninger (2011) describes how civic conventions underpin practices of healthy cooking.

Cultural understandings are not typically particular to a certain field of practice but are found across large parts of society, exemplified in our data by references to honor, bravery, manliness, economic necessity, fairness, or safety, all of which were made for or against attempts to change the practice's timeflow in some way. We emphasize that what we call cultural understandings are not rules or scripts that dictate a certain timeflow. Rather, these understandings are ideal types invoked for judging the performance or experience of practitioners (i.e., the fun of playing might be lost if a game is too hectic or too boring) and on behalf of which changes to or management of practices is attempted. For example, discourse critical of the fast-food industry contributed to the formulation of the slow-food movement (Ho- nore 2004), with obvious implications for the timeflow of eating.

As would be expected with regard to social discourses (Humphreys 2010) or negotiations of community norms (Arsel and Thompson 2011), conflicting tropes or values often arise. One example is the ongoing struggle to position the practice of paintball as a sport rather than a war game so as to shield it from public mistrust and mainstream media criticism:

We're often suffering from a negative image. Many think that we're some war-playing fascists. But it's not the case. You cannot see any camo [camouflage] clothes here. It's a real sport with proper rules and codes. We also have team jerseys like in football. (Francis, pro, 20+ years of experience, France)

In an effort to conform to the modern, Western understanding of sport, several changes were made to the bundle of elements in paintball. To align with a certain cultural understanding, practice elements were amended, not only by changing symbolic aspects such as the color of clothing but also by introducing "proper rules" and moving the game arena from woods or ruins into spectator arenas. These measures subsequently influenced the timeflow of the practice, in part because a small, open arena intensifies game play compared to a large wood with many hiding places. In a similar development, technological advances have led to a steady increase in the firing rate of paintball markers, which has a direct impact on the speed of the game play. Eventually, the increased speed led to a misalignment between the different elements of paintball:

The technology behind the sport has evolved tremendously. . . . For example, 10 years ago we were shooting semiautomatic guns . . . that wouldn't feed as fast as what we have today. And the organization behind the sport, the tournaments and the fields and the stores, it has evolved some but not in the same pace as what the technology behind it has evolved. (Steve, ex-pro, 15+ years of experience, United States)

In response to calls for decelerating the firing speed, manufacturers initially insisted that in providing high firing speed they were simply responding to consumer demand. Over time, however, arguments prevailed regarding the safety of the players, as well as the need for the sport to be "family-friendly" and thus attractive to larger customer segments. The material elements of paintball were thus finally altered to slow the game play. We therefore observe that different cultural understandings often bear on a practice simultaneously, fueling both the evolution of the practice and possible conflicts among practitioners. Changes to the timeflow of the practice might be at the heart of such struggles, as when freeskiers argue that high-rotation speed is detrimental to expressing style. 


\section{Misalignment of Elements Causes Experiences of Drag or Rush}

We have demonstrated that all five elements of consumption practices have an effect on the temporal experience of the practitioner, and we have emphasized that these elements never occur in isolation, but rather carry the conduct of a practice as an organized bundle. The effect an element has on the timeflow of a practice thus depends on its interplay with the other elements in the bundle. As we have shown, the effect of one element can sometimes be offset by the counter-effect of another one, as when bodily skill can make up for suboptimal equipment. Consequently, we argue that understanding how consumption practices shape temporal experience through timeflow critically depends on observing the relationship between practice elements rather than their qualities taken in isolation. In this section, and together with further data presented in table 2, we therefore examine how the relationships between practice elements shape experienced temporality. We distinguish between two basic types of relatedness that are illustrated in figure 4: alignment and misalignment. When all elements of a practice are aligned, no single element (or characteristic of it) "sticks out" of the overall smooth experience of the practitioner. A misaligned element, in contrast, is an element that demands attention, because it is experienced as hindering, threatening, or harming proper performance. Misalignment can occur in varying degrees. While complete misalignment equates to the breakdown of conduct (such as a skier crashing), subtle misalignment is a common feature of everyday conduct.

From a practice perspective, "social practices consist of elements that are integrated when practices are enacted" (Shove et al. 2012, 21). Performing a practice essentially means integrating the elements present in the situation at hand in such a way that current conduct amounts to the performance of that particular practice. Because every situation is riddled with certain contingencies and constraints, the fit between elements is seldom perfect but usually requires various degrees of improvisation, even though much of this alignment work happens in a routinized way below the radar of consciousness. For example, skiing, like walking, requires constant monitoring of balance and an ongoing adaptation of body movements to the surrounding material and the intended goal. But skillful skiers, like skillful walkers, rarely become consciously aware of a need for subtle and swift measures to avoid falling. However, our data suggest that despite such alignment work happening at the periphery of attention, small misalignments can still modulate experience. One could even speculate that the experience of temporal tension functions as an alert mechanism signaling that a misalignment requires attention.

As our findings summarized in table 2 show, practitioners describe the experienced temporality of a performance during which practice elements are misaligned differently from that during aligned performances. Misaligned performances are described as "too fast," "sketchy," "difficult," and "demanding" but also "too slow" and "not interesting." Other descriptors from our data include "hectic," "fragile," "boring," and "dull." These experiences fall into two broad categories since too much or too little seems to happen over the course of a temporal episode. Generalizing from our cases to consumption practices of all kinds, we introduce the terms rush and drag to describe such tense temporal experiences, building on two notions from music theory that describe unplanned and transient deviations from the current tempo of a tune (Wang 2008). Per our definition, rush denotes the experience of meaningful events occurring in sudden succession noticeably more quickly than the current pace of events. This speed often evokes a drastic narrowing of the perceived action-present, "the zone of time in which action can still make a difference to the situation" (Schön 1983, 62). The ensuing sense of loss of control is often perceived negatively (as stressful, hectic, or feverish), although the literature on so-called edgework suggests that some consumers actively seek out the extreme experience of rush in practices such as skydiving (Celci et al. 1993; Lyng 1990).

Drag, on the other hand, is a pace of events that is slower than the current or normal flow of conduct, which is thus experienced as delayed, hampered, or impeded. While practices of waiting are often accompanied by experiences of drag in Western everyday lives, freeskiers embrace waiting as a positive part of their sport. Another example is the normalization of patient waiting in other cultures (Levine 2008), showing that "negative waits" (Maister 1985) are not caused by the temporal elongation of the practice performance per se but rather by the occurrence of drag.

Importantly, rush or drag can occur with regard to any given speed of a timeflow, as when a freeskier explained how he had "a lot of time" during an episode of movement that took less than a second. A consumer who has been relaxing on the beach for a full day can feel rushed by having to get ready for dinner within half an hour, but might experience drag by having to wait for ten seconds for a website to load. The temporal experience of rush or drag emerges from a deviation from the flow of the current conduct, and not with regard to absolute time passed. Understanding consumer dissatisfaction caused by rush or drag, in other words, requires attending to timeflows, not time per se.

We theorize that when misalignments evoke an interruption of experienced temporality, peculiar and uneasy experiences occur, such as frenzy, stress, dullness, or boredom. In such situations something seems out of balance. Something does not fit into the current situation-be it a computer taking too long to open a file, the body being out of breath, or someone walking too slowly in front of you. We therefore propose that temporal experiences of rush and drag result when practice elements become misaligned. In contrast, temporal experience remains normal or unremarkable as long as elements align smoothly. We observe that in situations of perfect alignment, such as a romantic date, an idle day on the beach, or a few minutes of skillful meditation, we "forget the time" and the temporal dimension of our experiences recedes fully into the background. Experiencing 
TABLE 2

TIMEFLOW ELEMENT'S ALIGNMENT AND MISALIGNMENT

\begin{tabular}{l} 
Element \\
Example for effect of misaligned element \\
\hline Material set-up \\
PB: "I think we have lost a bit the pleasure of playing \\
paintball guns]. . . Even if you're a good player, \\
sometimes you can find in front of you a bad player \\
just hiding behind his gun." (Maurice, ex-pro, 20+ \\
years, FRA) \\
FS: "That [half-]pipe is crap; it is too small. . . You \\
have no time to correct your body position. If you [lose \\
balance] once, it gets worse and worse and then you \\
crash." [Having enough time to correct your body posi- \\
tion would still be less than a second.] (Phillip, pro, 12 \\
years, AUT) \\
PB: "You need to be young and strong and fast. The de- \\
mands are quite high. You need to be able to run \\
from this part of the field to that part of the field in un- \\
der three seconds. If you're not that fast you're not \\
gonna play paintball." (Dirk, ex-pro, 10+ years, US) \\
FS: "You are doing way too much! You should be using \\
your arms only for the [rotation] impulse; you don't \\
need your upper body. . . Otherwise it all will be \\
way to fast [and you crash]." (Phillip, pro, 12 years, \\
AUT) \\
PB: "At the moment, there's a lot of things going on in \\
the field-maybe even too many things-so that \\
someone who is not familiar with the sport would not \\
be interested. Unfortunately." (Rami, semipro, 15+ \\
years, FIN) \\
Rules
\end{tabular}

FS: "A Jam Session [contest format] actually means every rider can have as many runs as he wants within two hours. . . . But [one time] whenever one had a run they said 'Stop!' and judged him [according to a point system], which took more than a minute. Everybody had to stand around [to wait] and nothing happened. . . . That was really far removed from what freeskiing should be." (Phillip, pro, 12 years, AUT)

Teleoaffective structures

PB: "Before it was a bunch of friends who were playing together . . . there was a place for everybody in paintball, this was a very good part. It is still the case in the recreational market, you can still play with your son and your father. But on the tournaments it's finished. Now you need to take it seriously." (Maurice, ex-pro, 20+ years, FRA)

FS: "The slower I am, the less airtime I get; and when I am too slow, it hurts really badly when I crash. . . . And the main problem is . . . that fear slows you down. . . . You break just before the kicker although you did not want to. . . . That is a vicious circle [in that the fear of crashing causes the crash]." (Tom, semipro, 14 years, GER)

Example for effect of aligned element

PB: "It's why we've gone to 12 balls per second [15 balls per second previously]. My opinion would be to go to 10. It allows more movement . . . for the spectators but also for the play. . . . We need to see the good player who can do a crazy move and shoot 3-4 players." (Maurice, ex-pro, 20+ years, FRA)

FS: "This kicker is a really well-shaped; it has a really nice transition. So it gives you a nice pop, which means you get perfect airtime. That is because it is a tabletop-kicker [a special shape]." (Tom, semipro, 14 years, GER)

PB: "As you get better, you start to see those moves ahead of you. . . . That's when you can see amazing moves that someone planned already twenty, thirty seconds ago before actually doing them." (James, pro, 14 years, CAN)

FS: "If I am doing a 540 [trick] and I still have a lot of time before landing, then I know right away: 'Ok, now I can [advance to a more difficult trick and] add half a rotation more."' (Tom, semipro, 14 years, GER)

PB: "[In the past] the games were longer. That was quite a different experience. If you were a player who understood the game, you could do really interesting moves. It felt like there was so much more space in the game. It was not only because the distances were physically longer in the field but there was more space for you, more time to think and act." (Rami, semipro, 15+ years, FIN)

FS: "Generally, [contest judges] pay a lot of attention . . . to the number of rotations [and thus speed] . . But there are also the contests where they purposefully ban anything above 540 [rotations per jump to slow the movements down]. The only thing that counts . . . is how it looks." (Tom, semipro, 14 years, GER)

PB: [l: How much is it about the winning?] "All of it. . But I guess it is different for everyone, as people bring so much of their everyday lives into this sport. What my experiences are might be different to someone else's. We train every week, throughout the week we're all on phones on each other. It's everything really. Your life goes on hold over paintball." (Glen, amateur, 8 years, UK)

FS: "I need my music, that is really important, so that I can find my groove. . . . If I am at a large kicker where I need to go at it with full speed, for example, then I like to listen to aggressive punk rock. . . . That really pushes you, and then I go for it." (Anna, amateur, 6 years, GER) 
TABLE 2 (Continued)

\begin{tabular}{|c|c|c|}
\hline Element & Example for effect of misaligned element & Example for effect of aligned element \\
\hline \multirow[t]{2}{*}{$\begin{array}{l}\text { Cultural } \\
\text { understandings }\end{array}$} & $\begin{array}{l}\text { PB: "[Back in the days] . . . it was like we played two } \\
\text { days in a row. We were constantly there, either play- } \\
\text { ing or watching others play and supporting them. Now } \\
\text { we'd have one game in the morning and one in the } \\
\text { evening and we'd go away in between them. It might } \\
\text { be more convenient for the players but you kind of } \\
\text { lose the same tournament feeling we used to have. } \\
\text { The feeling is not the same at all." (Jan, semipro, 15+ } \\
\text { years, FIN) }\end{array}$ & $\begin{array}{l}\text { PB: "Like for the Sunday [final day of tournament] } \\
\text { games, if you can make it there, the first game is } \\
\text { the most important one. Because if you can build a } \\
\text { good game feeling there it will carry you through- } \\
\text { out the day as the games are only one or two } \\
\text { hours apart. There is always a very limited time } \\
\text { between them. This is the best feeling you would } \\
\text { get. You want to build this flow between and } \\
\text { through the games." (Pete, semipro, 15+ years, } \\
\text { FIN) }\end{array}$ \\
\hline & $\begin{array}{l}\text { FS: "We got three judges here that pay close attention } \\
\text { to what you do and how you do it. Whatever you do, } \\
\text { do it with style. . . And especially do it safely! . . . } \\
\text { So better take it slow and rotate nicely and clean, in- } \\
\text { stead of over-rotations. . . and sketchy landings. You } \\
\text { know what I mean!" (A judge explaining the contest } \\
\text { rules, GER) }\end{array}$ & $\begin{array}{l}\text { FS: "No matter if you are just riding or taking part in } \\
\text { a contest, it is never the goal to be perfect in } \\
\text { terms of technique, but to be as stylish as possible } \\
\text { - to bring across the coolness factor. That is al- } \\
\text { ways the goal, and that is what I find so great, that } \\
\text { it is not about being higher, faster, further." (Sa- } \\
\text { brina, amateur, } 5 \text { years, GER) }\end{array}$ \\
\hline
\end{tabular}

NotE.-AUT = Austria; CAN = Canada; FIN = Finland; FRA = France; FS = Freeskiing; GER = Germany; PB = Paintball; UK = United Kingdom; US = United States.

time thus seems to be a practitioner's way of noticing the subtle misalignments that accompany much of our everyday lived life, which is characterized by multiple tasks and constraints. In contrast, time disappears in those rare moments of what Csikszentmihalyi (1990) calls optimal conduct.

The notion of timeflow we offer is distinct from, but useful for explaining the phenomenon of flow experiences, which is an effect of optimal conduct. Flow is a transcendent state of emotion framed as the manifestation of a person's "true" self and can be described as a moment with "no sense of time, just a kind of holistic oneness that makes [one] feel good and somehow changed" (Celci et al. 1993, 11) A flow experience occurs if the stimulus field is limited and scripted by the individual so that the situation demands total involvement (Celci et al. 1993; Goulding et al. 2009). Accordingly, the state of flow and the timeflow of consumption practices are not identical. Flow denotes an extraordinary temporal experience, whereas timeflow is a general framework to account for all forms of experienced temporality. From a timeflow perspective, research into flow phenomena confirms the assumption that temporal experience during an activity depends on a combination of the situational setting, given ends or rules, and emotional states. It also suggests that if these elements align perfectly, the absence of rush or drag can be so complete that the temporal dimension of experience retreats fully into the background. Moments of complete alignment, however, were rare in our data.

Because freeskiing is a set of dangerous and fragile practices, it offers the possibility to examine the nature of misalignments and the temporal experience they induce in more detail. Performing freeskiing frequently ends in a crash, which is caused by small misalignments between the elements. For example, lacking just a little speed when going over a kicker means that "you jump too short, and then it really hurts" (Tom, semipro, 14 years of experience, Germany). But rather than being rooted in mono-causal factors, misalignments always concern the relationship between el- ements. For example, the type of ski and the size of the kicker might be a mismatch, or the skier may have intended one trick, but out of habit made a move belonging to a different trick, or the music he or she listened to did not instill the emotional attitude required for full speed. For this reason, freeskiers carefully check the current conditions of various dimensions before attempting dangerous stunts. In the various practices freeskiers conduct throughout the day-which also include waiting, watching, or just cruising around-not every small misalignment of elements causes a complete breakdown or crash. However, we noted that, like many other practitioners including paintball players, freeskiers can forget the time (for some minutes or even hours) if things are going perfectly. In contrast, we also found that whenever something was wrong, the temporal dimension of their experience became much more acute or present - and usually not in a good way. Sitting in a chairlift while really wanting to go ahead and do another jump, for example, would make time seem to drag on much too slowly. The typical recollection of a crash, in contrast, consists of something happening in a sudden rush that is difficult to recollect afterwards. The loss of control, in other words, is reflected in the temporal experience. Our data thus suggest that pronounced or tense temporal experiences (such as something happening unusually fast or slowly) are the modus through which we experience the largely routinized, preconscious management of the misalignments of practice elements during conduct. We conclude that it is by virtue of inadequacies of experienced temporality that imbalances in the bundle of elements of the current practice performance are felt by us.

We emphasize that in our model, drag or rush are effects occurring in particular situations of conduct owing to a misalignment between the elements involved at that particular moment. Rush and drag are not general features of the timeflow of a certain practice, nor do they inevitably occur in a certain locale or servicescape. It is key to remember that 


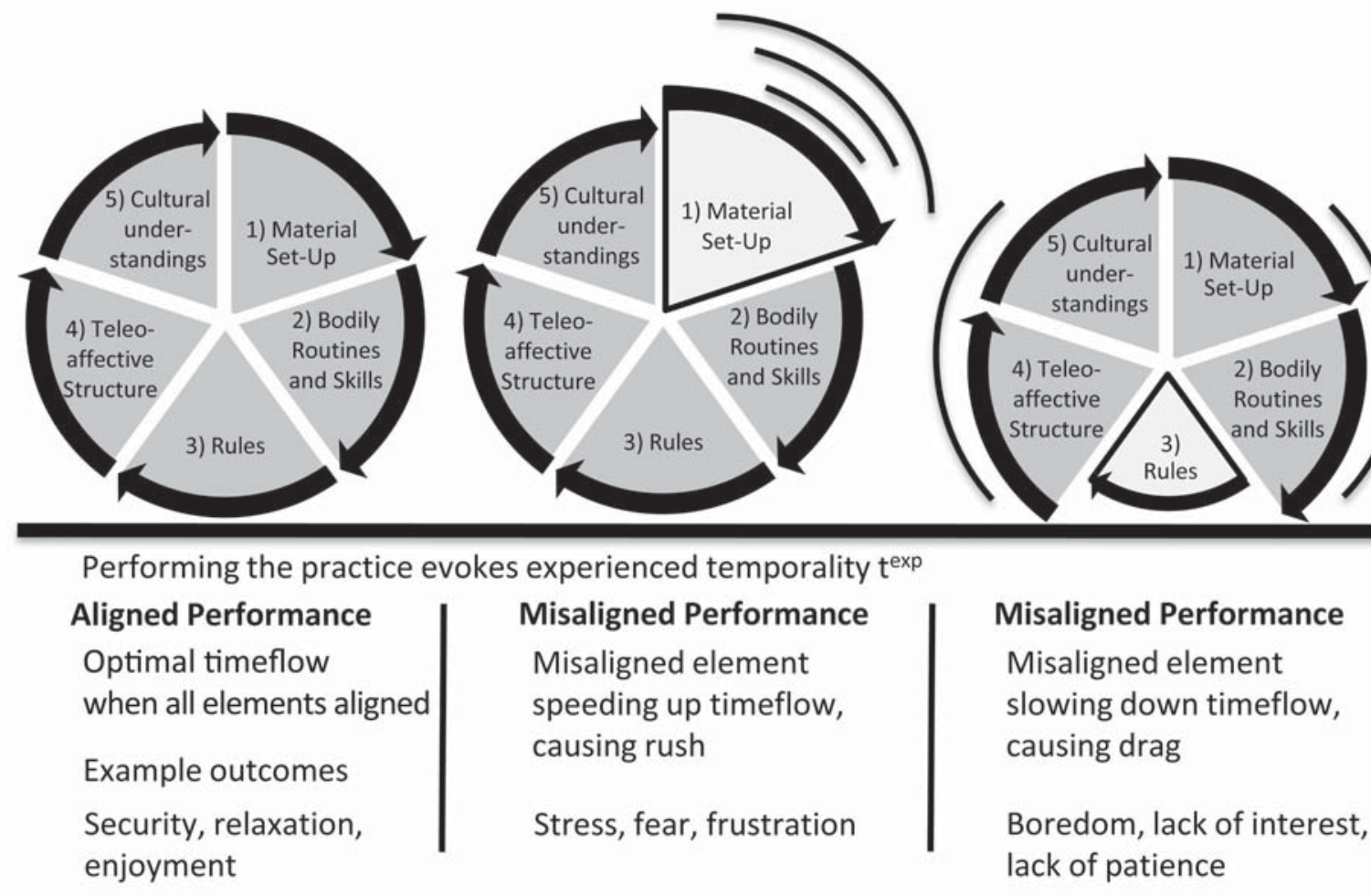

rush and drag are effects of how the overall constellation of elements at that particular moment fits together. Therefore, a deficiency in one element can be made up by another element, as when particularly user-friendly equipment enables smooth conduct despite the introduction of new and especially challenging rules. Per our definition, the timeflow of a practice is the temporal interrelation of meaningful events occurring in the course of the ongoing normal conduct of that practice. Local contingencies and difficulties can cause an abnormal or problematic course of conduct, which we then expect to be accompanied by rush or drag. According to our model, learning a new practice such as driving a car often makes consumers feel rushed or stressed, because they lack the skills to smoothly integrate the different elements such as operating the car while following the rules of the road. Again, timeflow as a general feature of a practice can be rapid or slow, while rush and drag are transient and tense experiences. If consumers' temporal experience is negatively affected by rush or drag, our model accordingly implies that the situation can be improved by avoiding misalignments that might occur in the way consumption practices are performed locally.

\section{Versions of Practices-Distinctive Timeflows}

Not surprisingly, frequent occurrences of misalignments and thus agitated or pronounced temporal experiences can drive the change of practices. Given that our data include many references to variations of the studied consumption practices, a question arises as to when a practice is considered an entirely different practice or a different version of the same practice. Our data illuminate several co-existing forms of practices that have gradually evolved and thus have distinct timeflows.

Present-day tournament paintball, also known as "speedball" or "X-ball," is a twist from the original form called "woodsball" or "scenario paintball," initially played in the woods rather than on artificial standardized fields. Practical considerations called for making the game more accessible to different players and audiences. The forest presented logistical problems related to efficient game play and equipment, and following the sport as a spectator was nearly impossible. While a more compact tournament format and shorter games made paintball more popular, the original format has retained its appeal to some partly because of the distinct experiences: 
Scenarios are above all fun. . . You're not really trying to win the first place. In contrast, in the competition format, everything is fast paced. You're under a lot of pressure, it's about winning. . . However, in the scenario play you can be crawling through the woods for half an hour and never see anybody for a while. So it's really a different pace and also a different fun. (Dirk, ex-pro, 10+ years of experience, US)

Consumer research has established that multiple versions of the same consumption practice can co-exist simultaneously, such as different ways of cooking (Truninger 2011), running (Thomas, Price, and Schau 2013), surfing (Canniford and Shankar 2013) or riding motorbikes (Martin and Schouten 2013). Like paintball, freeskiing has undergone a proliferation of genres, most importantly owing to different competitive formats, styles, and varieties of kickers. We therefore specify our theoretical proposition that performing consumption practices induces a temporalized experience because of their timeflow by stating that different versions of practices can have different timeflows. A version of a practice shares the same core bodily skill or practical understanding (the same basic types of doings and sayings that amount to performing the practice) as other versions of the same practice, but differs in that it contains elements that are distinct, such as different rules (as with Olympic freestyle skiing) or a different material set-up (e.g., urban freeskiing; Schatzki 2002; Warde 2013). From a purely theoretical standpoint, it is not immediately evident why the core bodily skills should be treated as definitive for distinguishing different versions of the same practice from two different practices. Empirically, however, our respondents use exactly this notion to describe different versions of what for them is evidently and unproblematically the same practice:

Regarding the game styles, no matter what, if the object is to shoot the other player, it's still paintball. Whether you're playing in the woods, whether you're playing a pump-gun, whether you're playing X-ball, it's basically all "shoot the other player." And that's basically where the thrill of it and enjoyment comes from. (James, pro, 14 years of experience, Canada)

As Warde (2013) argues, treating core bodily doings as definitive for practices is indeed widely reflected in our everyday use of language. For example, in both slow-food and fast-food dining, the basic identity of eating is not called into question. The idea that the same practice can be assembled by various configurations of different elements, which can then be categorized into several normal variants of the same practice, is common sense to practitioners. Eating, for example, can be done with knife and fork, by hand, or with sticks, and it can require various ceremonial routines or specific spatial settings. Still, members of different cultures or epochs will not have trouble identifying eating in any context, and will most likely even agree on borderline cases such as chewing (rather than eating) gum.

\section{CONTRIBUTIONS AND IMPLICATIONS}

\author{
Contributions to Research on Temporality
}

More than two decades have passed since Kellaris and Kent $(1992,374)$ first urged consumer researchers to "investigate the experience of a duration from a concurrent perspective." We have taken on this challenge by proposing a theoretical model that accounts for temporal experiences among consumers through the consumption practices being performed, rather than through an orientation or timestyle of the individual (Bergadaà 1990; Cotte et al. 2004; Feldman and Hornik 1981) or group (Brodowsky et al. 2008). The primary contribution of this article is the theoretical bridging of the gap between practices and temporal experiences through the conceptualization of timeflow, or a consumption practice's ability to induce a certain typical temporal experience whenever it is performed.

Experimental research has established that consumers' temporal experience during an activity can be manipulated by contextual factors present in the situational environment. By introducing the notion of the timeflow of social practices, we move from attending to isolated contextual variables toward a holistic understanding of experienced temporality as occasioned or keyed by the overall situational embedding of a consumption activity. A holistic phenomenological perspective toward time and temporality can help overcome a particularistic view of temporality, but raises the danger of arriving at a dichotomy of "outer" universal and "inner" subjective time. This dichotomy forces authors to treat time in one of two limited ways. Time may be framed as universally homogenous and happening independently of consumption activities, thus making it impossible to discriminate between differences in temporal flows, experiences, or contextual embedding across different consumption activities. Alternatively, time may be taken to be a purely subjective inner experience, which excludes contextual or environmental factors located outside the sphere of consciousness from the theoretical model. As a solution, we have proposed a framework that is neither particularistic nor subjectivist, because it treats temporal experience as an effect of performing consumption practices.

The notion of the timeflow of consumption practices can explain a range of phenomena in a theoretically coherent manner. First, distinguishing between universal time and timeflow leaves the ontological status of time per se untouched and does not create contradictions with existing research into the timing of consumption (when and how often consumers consume). Second, defining timeflow as a quality for the practitioner but of a practice acknowledges subconscious, material, bodily, and situational influences on experienced temporality as pervasive, relevant, and variable factors instead of treating them as epiphenomena to an assumed consciousness of inner time.

We have illustrated how the material set-up, bodily routines and skills, rules, teleoaffective structures, and cultural understandings of consumption practices directly and in concert shape the timeflow of practices and thus the temporal 
experience of the consumers we studied. We suggest that systematically exploring or testing distinctive configurations of practice elements will allow consumer researchers to account for the nature of and changes in the temporal experiences of consumers across a broad range of practices. We emphasize that our model is not restricted to service experiences, and that it can also be used to study the influence of products on experienced temporality. For example, future research might ask how carrying a smartphone changes the temporal experience of traveling on a bus or train.

Finally, we call attention to the effects of alignment and misalignment of practice elements as potential cues for explaining the attractiveness and vitality of consumption practices. In our study, consumers referred to misaligned elements that were causing a drag or rush as an experience often associated with boredom or stress. Such instances would thus stick out as hindrances or curbs disrupting the regular temporal flow of performing a practice. When elements were perfectly aligned, on the other hand, a smooth temporal flow unfolded, relegating temporality almost entirely to the background from a practitioner's point of view. Understanding consumer dissatisfaction caused by rush or drag thus requires attending to timeflows, not time per se. Recognizing experienced temporality as an effect of interconnected practice elements and their alignment has implications for research into issues such as waiting, the consumer experience, or marketplace rituals, as outlined in table 3 .

\section{Contributions to Research on Servicescapes}

The antecedents and effects of consumers' temporal experience have been studied in great detail with regard to servicescapes (Baker and Cameron 1996; Durrande-Moreau 1999; Taylor 1994), and in particular customer waiting. However, although the perceived environment of the servicescape is occasioned by "the total configuration of stimuli" (Bitner 1992, 65), servicescape elements have been studied primarily in isolation and as independent factors (Ezeh and Harris 2007). We propose that this incongruence can be remedied by shifting the unit of analysis from isolated causal effects on individual behavior to consumption practices. We believe that attempts to ascribe forces of causal determination to contextual embeddings are generally misguided, because their effects frequently overlap or cancel each other out (Askegaard and Linnet 2011), and we suggest that researchers study how servicescapes condition consumer behavior, rather than causing it. Our novel framework accounts well for past findings regarding isolated effects of stimuli, such as music, by pointing to the importance of sensory "enwrapping" for embodied routines (e.g., music beats influence heartbeat and breathing) and pre-reflective moods (e.g., happy vs. sad music styles).

However, our framework also adds two caveats to the existing research on experienced temporality in servicescapes. First, not all elements of servicescapes can be expected to have unidirectional and stable effects, especially without consideration of the overall situational set-up. For example, our model suggests that the effect of background music on shopping does not depend only on features of the music itself (such as tonality), but rather on the way it aligns with the overall composition of the shopping context, including cultural understandings or shoppers' teleological orientations. Second, our framework directs attention to the

TABLE 3

POTENTIAL CONTRIBUTIONS OF RESEARCH ON TIMEFLOW OF CONSUMPTION PRACTICES

\begin{tabular}{|c|c|c|}
\hline $\begin{array}{l}\text { Area of consumer } \\
\text { research }\end{array}$ & Traditional approaches to temporality & Timeflow approach \\
\hline $\begin{array}{l}\text { Consumption } \\
\text { experiences }\end{array}$ & $\begin{array}{l}\text { Experiences are characterized by a certain rhythm and } \\
\text { tempo (Arnould and Price 1993; Goulding and Shan- } \\
\text { kar 2009; Celci et al. 1993; Pink 2007). }\end{array}$ & $\begin{array}{l}\text { Different consumption practices induce particular } \\
\text { timeflows and changes in practice elements mod- } \\
\text { erate these timeflows. }\end{array}$ \\
\hline Servicescapes & $\begin{array}{l}\text { The physical and atmospheric environment of service } \\
\text { and retail space influences temporal experience (Ar- } \\
\text { nould 2005; Bitner 1990; 1992; Baker and Cameron } \\
\text { 1996; Hui et al. 1998). }\end{array}$ & $\begin{array}{l}\text { Servicescape may accommodate distinctive time- } \\
\text { flows, depending on the consumption practice con- } \\
\text { sumers engage in. Misalignments between practice } \\
\text { elements cause experiences of drag or rush. }\end{array}$ \\
\hline Waiting & $\begin{array}{l}\text { Changes in physical and atmospheric elements may in- } \\
\text { fluence perceived waiting time (Kellaris and Kent } \\
\text { 1992; Taylor 1994); individual personality, mood and } \\
\text { affective states (Hornik 1993), or coping strategies } \\
\text { moderate it (Miller et al. 2008). }\end{array}$ & $\begin{array}{l}\text { Not all waiting practices entail experiences of drag or } \\
\text { rush. Drag and rush are not controlled by isolated } \\
\text { variables but by an effect of the misalignment be- } \\
\text { tween practice elements. They can be avoided by } \\
\text { ensuring alignment. }\end{array}$ \\
\hline $\begin{array}{l}\text { Leisure, sports, media } \\
\text { audiences }\end{array}$ & $\begin{array}{l}\text { Individuals have distinctive timestyles influencing how } \\
\text { they personally relate to leisure activities (Bergadaa } \\
\text { 1990; Cotte et al. 2004). }\end{array}$ & $\begin{array}{l}\text { Timeflow does not depend as much on personal } \\
\text { characteristics as on the nature of the consumption } \\
\text { practice. Alignment of practice elements shapes } \\
\text { these experiences. }\end{array}$ \\
\hline $\begin{array}{l}\text { Consumption rituals, } \\
\text { routines, practices }\end{array}$ & $\begin{array}{l}\text { Consumers allocate time across various activities, rou- } \\
\text { tines, rituals and practices (Shove et al. 2009), and } \\
\text { multitask between them (Kaufmann et al. 1991). }\end{array}$ & $\begin{array}{l}\text { Consumers' everyday life is characterized by different } \\
\text { timeflows and conjunctions between them. Differ- } \\
\text { ent versions of the same consumption practice } \\
\text { may have distinctive timeflows. }\end{array}$ \\
\hline $\begin{array}{l}\text { Markets, market } \\
\text { evolution }\end{array}$ & $\begin{array}{l}\text { New markets may emerge owing to changes in temporal } \\
\text { resources companies employ in crafting new market } \\
\text { offers (Arnould 2005). }\end{array}$ & $\begin{array}{l}\text { Changes in consumption practice's timeflow may re- } \\
\text { sult in new markets. Timeflow's attractiveness for } \\
\text { consumers and media audiences can propel mar- } \\
\text { ket growth. }\end{array}$ \\
\hline
\end{tabular}


fact that previous research presupposes the prevalence of a certain universal practice, such as the practice of shopping. We argue that researchers should pay attention to possible variations across different versions of a practice. In the case of shopping, variations could be high- versus low-involvement shopping, or intuitive decisions about style or taste versus a focus on price and utility. The shift in the unit of analysis we propose would not only lead researchers to bundle factors that are co-constitutive, but would also sensitize them to differentiate divergent (versions of) practices that can take place side by side within the same servicescape. Future research could examine how certain servicescape designs afford or hinder the performance of different practices characterized by unique timeflows. Further, we would also argue that analyzing timeflows has the potential to alert managers to the need for improving the servicescape design, and we invite them to adopt a more holistic view of the moderators of temporal experiences.

\section{Contributions to Research on Everyday Consumption and Extraordinary Flow Experiences}

We introduce timeflow as the ability of a practice to evoke temporal experience. Therefore, we refer to a phenomenon, which is different from the temporal ordering of sets or bundles of practices that a number of authors have commented on (Shove et al. 2009). Also, we are not directly concerned with the distribution of practices over a given time span, such as analyses of consumers' time logs documenting time spent for certain activities, like hours of watching TV per day (Kaufman et al. 1991). However, we do believe that insights into the timeflow of consumption practices could provide important clues for such studies, for example answering the question of why people get stuck in front of the TV so easily.

Accordingly, research into timeflows could add to the discussion about temporal regimes of everyday life and the temporal coordination of social practices (Jalas 2006; Southerton 2006; Shove et al. 2009). Additionally, further research guided by our framework could help to account more systematically for the antecedents of particularly powerful flow experiences during consumption (Celci et al. 1993; Csikszentmihalyi 1990; Goulding et al. 2009) by comparing flow to more mundane, non-flow experiences evoked by different versions of the same practice, such as listening to music in a club (Goulding et al. 2009) versus listening in a bar. Furthermore, analyzing the elements influencing timeflow may prove useful in the quest for achieving or maintaining a flow state. In our study, a misalignment of elements typically implied that a potential flow state had either broken down or was at least kept at bay.

\section{FUTURE RESEARCH DIRECTIONS}

Since temporality can be a decisive dimension of consumption experiences, research into timeflow can stimulate advances for furthering the ongoing debate on why certain consumption practices diffuse more successfully than others (Shove and Pantzar 2005), and how they attract media audiences or can be successfully packaged as spectacles for these audiences (Kozinets et al. 2004; Nandy 2000). Studying the timeflow of practices can open up fruitful avenues for future research that deepens our understanding of the long-term changes of consumption practices (Arsel and Thompson 2011; Shove et al. 2012) and market systems (Giesler 2008; Humpreys 2010; Martin and Schouten 2014). We propose that effects of a change in timeflow are connected to the consumer segments attracted to it. In both freeskiing and paintball, slower and easier forms have evolved, built on adapted technologies and rules, helping to draw beginners to the practice. Such developments can be seen to reflect the need for addressing the heterogeneity of practitioners (Thomas et al. 2013). Consequently, as with slow food, different products and services tailored to new groups of practitioners will likely be marketed.

A second avenue for future research lies in studying how timeflow influences the audience attractiveness of a practice. Our data suggest that the timeflow of a practice is not only crucially important to practitioners engaged in an activity, but also to those watching the performance of a practice, be it live or via media. First, this point is directly relevant to all sports that draw audiences or are covered on TV or video-based media. Second, the timeflow concept could be transferred to the study of media use more generally, as the timeflow of watching TV shows, movies, or online videos is arguably highly relevant for the attractiveness of different genres meant to induce tension, relaxation, anticipation, and so on. Third, we speculate that the audience attractiveness of consumption practices resulting from a certain timeflow is relevant to all consumption activities that entail some kind of performative quality, in particular consumption rituals (Wallendorf and Arnould 1991), interactive forms of identity play (Diamond et al. 2009), and status display (Schouten and McAlexander 1995).

\section{DATA COLLECTION INFORMATION}

Both authors carried out ethnographic fieldwork independently but with similar methods and aims from 2008 until 2010. In 2010, they noted structural similarities with regard to the theme of time in their data and began collaboration. They collected, shared and compared all observational, visual and interview data with reference to temporality, and sensitized by a practice theory framework, discussed emergent themes. From 2010 to 2013, temporal phenomena became a focus of their continued fieldwork. Patterns or open questions that had emerged from existing data were used to stipulate further inquiry. In this phase, three main data sources were utilized. First, video analysis was conducted by the first author: naturally occurring interactions were videotaped and the visual and verbal structure of critical moments was transcribed in very high detail. Second, both authors systemically collected references to temporality in subcultural media documents such as films 
or magazines. Third, in the final phase of fieldwork in 2012 and 2013, interviews with key informants where conducted specifically on questions of time use and temporal experience, and informants were asked for feedback on key themes (e.g. the role of waiting, or misalignment). A triangulation procedure was then used to develop the theoretical model. The final analysis was jointly authored.

\section{REFERENCES}

Arnould, Eric J. (2005), “Animating the Big Middle," Journal of Retailing," 81 (2), 89-96.

Arnould, Eric J., and Linda Price (1993), "River Magic: Extraordinary Experience and the Extended Service Encounter," Journal of Consumer Research, 20 (June), 24-45.

Arnould, Eric J., and Craig J. Thompson (2005), "Consumer Culture Theory (CCT): Twenty Years of Research," Journal of Consumer Research, 31 (March), 868-82.

Arsel, Zeynep, and Jonathan Bean (2013), "Taste Regimes and Market-Mediated Practice," Journal of Consumer Research, 39 (February), 899-917.

Arsel, Zeynep, and Craig J. Thompson (2011), "Demythologizing Consumption Practices: How Consumers Protect Their FieldDependent Identity Investments from Devaluing Marketplace Myths," Journal of Consumer Research, 37 (May), 791-806.

Askegaard, Søren, and Jeppe Trolle Linnet (2011), "Towards an Epistemology of Consumer Culture Theory," Marketing Theory, 11 (4), 381-404.

Baker, Julie, and Michelle Cameron (1996), "The Effects of the Service Environment on Affect and Consumer Perception of Waiting Time: An Integrative Review and Research Propositions," Journal of the Academy of Marketing Sciences, 24 (4), 338-49.

Bergadaà, Michelle M. (1990), "The Role of Time in the Action of the Consumer," Journal of Consumer Research, 17 (December), 289-302.

Bergson, Henri (1911), Creative Evolution, trans. Arthur Mitchell, New York: Henry Holt.

Berry, Leonard K., Kathleen Seiders, and Dhruv Grewal (2002), "Understanding Service Convenience," Journal of Marketing, 66 (3), 1-17.

Bitner, Mary J. (1990), "Evaluating Service Encounters: The Effects of Physical Surroundings and Employee Responses," Journal of Marketing, 54 (April), 69-82.

___ (1992), "Servicescapes: The Impact of Physical Surroundings on Customers and Employees," Journal of Marketing, 56 (April), 57-71.

Bloor, D. (2001), "Wittgenstein and the Priority of Practice," in The Practice Turn in Contemporary Theory, ed. Theodore R. Schatzki, Karin Knorr Cetina, and Eike von Savigny, London: Routledge, 95-106.

Brodowsky, Glen, Neil Granitz, and Beverlee Anderson (2008), "The Best of Times Is Now: A Study of the Gay Subculture's Attitudes toward Time," Time and Society, 17 (2/3), 233-60.

Canniford, Robin, and Avi Shankar (2013), "Purifying Practices: How Consumers Assemble Romantic Experiences of Nature," Journal of Consumer Research, 39 (February), 1051-69.

Celci, Richard L., Randall L. Rose, and Thomas W. Leigh (1993), "An Exploration of High-Risk Leisure Consumption through Skydiving," Journal of Consumer Research, 20 (June), 1-23.

Cotte, June, S. Ratneshwar, and David Glen Mick (2004), "The Times of Their Lives: Phenomenological and Metaphorical
Characteristics of Consumer Timestyles," Journal of Consumer Research, 31 (September), 333-45.

Csikszentmihalyi, Mihalyi (1990), Flow: The Psychology of Optimal Experience, New York: HarperCollins.

Darley, John M., and Daniel T. Gilbert (1985), "Social Psychological Aspects of Environmental Psychology," in Handbook of Social Psychology, Vol. 2, Special Fields and Applications, 3rd ed., ed. Gardner Lindzey and Elliot Aronson, New York: Random House, 949-91.

Diamond, Nina, John F. Sherry, Albert M. Muñiz, Mary Ann McGrath, Robert V. Kozinets, and Stefania Borghini (2009), "American Girl and the Brand Gestalt: Closing the Loop on Sociocultural Branding Research," Journal of Marketing, 73 (3), 118-34.

Durrande-Moreau, Agnès (1999), "Waiting for Service: Ten Years of Empirical Research," International Journal of Service Industry Management, 10 (2), 171-89.

Epp, Amber M., and Linda L. Price (2008), "Family Identity: A Framework of Identity Interplay in Consumption Practices," Journal of Consumer Research, 35 (June), 50-70.

(2010), "The Storied Life of Singularized Objects: Forces of Agency and Network Transformation," Journal of Consumer Research, 36 (February), 820-37.

Ezeh, Chris, and Lloyd C. Harris (2007), "Servicescape Research: A Review and a Research Agenda," Marketing Review, 7 (1), 59-78.

Feldman, Laurence P., and Jacob Homik (1981), “The Use of Time: An Integrated Conceptual Model," Journal of Consumer Research, 7 (March), 407-19.

Flick, Uwe (2008), Managing Quality in Qualitative Research. The SAGE Qualitative Research Kit, Vol. 8, London: Sage.

Frers, Lars (2007), "Perception, Aesthetics, and Envelopment: Encountering Space and Materiality," in Encountering Urban Places: Visual and Material Performances in the City, ed. Lars Frers and Lars Meier, Aldershot: Ashgate, 25-46.

Garfinkel, H. (2002) Ethnomethodology's Program: Working out Durkheim's Aphorism, Lanham: Rowman.

Giesler, Markus (2008), "Conflict and Compromise: Drama in Marketplace Evolution," Journal of Consumer Research, 34 (April), 739-53.

Gleick, James (1999), Faster: The Acceleration of Just about Everything, New York: Pantheon Books.

Gobo, Giampietro (2013), Doing Ethnography, London: Sage.

Goulding, Christina, Avi Shankar, Richard Elliott, and Robin Canniford (2009), "The Marketplace Management of Illicit Pleasure," Journal of Consumer Research, 35 (February), 75971.

Graham, Robert J. (1981), "The Role of Perception of Time in Consumer Research," Journal of Consumer Research, 7 (March), 335-42.

Heidegger, Martin (1962), Being and Time, trans. John Macquarrie and Edward Robinson, New York: Harper \& Row.

Hirschman, Elizabeth C. (1987), "Theoretical Perspectives of Time Use: Implications for Consumer Behavior Research," in Research in Consumer Behavior, ed. Jagdish N. Sheth and Elizabeth C. Hirschman, Greenwich, CT: JAI Press, 55-81.

Holbrook, Morris B., and Donald R. Lehmann (1981) "Allocating Discretionary Time: Complementarity among Activities," Journal of Consumer Research, 7 (March), 395-406.

Honoré, Carl (2004). In Praise of Slow: Challenging the Cult of Speed, San Francisco: HarperOne.

Hornik, Jacob (1984), "Subjective vs. Objective Time Measures: 
A Note on the Perception of Time in Consumer Behavior," Journal of Consumer Research, 11 (June), 615-18.

- (1993), "The Role of Affect in Consumer's Temporal Judgements," Psychology and Marketing, 10 (3), 239-55.

Hui, Michael K., Laurette Dube, and Jean-Charles Chebat (1997), "The Impact of Music on Consumers' Reactions to Waiting for Services," Journal of Retailing, 73 (1), 87-104.

Hui, Michael K., Mrugank V. Thakor, and Ravi Gill (1998), "The Effect of Delay Type and Service Stage on Consumers' Reactions to Waiting," Journal of Consumer Research, 24 (March), 469-79.

Hui, Michael K., Alan C. Tse, and Lianxi Zhou (2006), "Interaction between Two Types of Information on Reactions to Delays," Marketing Letters, 17 (2), 151-62.

Hui, Michael K., and David K. Tse (1996), "What to Tell Consumers in Waits of Different Lengths: An Integrative Model of Service Evaluation," Journal of Marketing, 60 (April), 81-90.

Humphreys, Ashley (2010), "Semiotic Structure and the Legitimation of Consumption Practices: The Case of Casino Gambling," Journal of Consumer Research, 37 (3), 490-510.

Husserl, Edmund (1991), On the Phenomenology of the Consciousness of Internal Time, trans. John. B. Brough, Dordrecht: Kluwer.

Jacoby, Jacob, George J. Szybillo, and Carol K. Berning (1976), "Time and Consumer Behavior: An Interdisciplinary Overview," Journal of Consumer Research, 2 (March), 320-39.

Jalas, Mikko (2006), "Making Time: The Art of Loving Wooden Boats," Time and Society, 15, 343-63.

Joy, Annamma, and John F. Sherry Jr. (2003), "Speaking of Art as Embodied Imagination: A Multisensory Approach to Understanding Aesthetic Experience," Journal of Consumer Research, 30 (September), 259-82.

Katz, Karen, Blaire Larson, and Richard Larson (1991), "Prescription for the Waiting in Line Blues: Entertain, Enlighten and Engage," Sloan Management Review, 32 (2), 44-53.

Kaufman, Carol Felker, Paul M. Lane, and Jay D. Lindquist (1991), "Exploring More than 24 Hours a Day: A Preliminary Investigation of Polychronic Time Use," Journal of Consumer Research, 18 (December), 392-401.

Kellaris, James J., and Robert J. Kent (1992), “The Influence of Music on Consumers' Temporal Perceptions: Does Time Fly When You're Having Fun?" Journal of Consumer Psychology, 1 (4), 365-76.

Knoferle, Klemens M., Eric R. Spangenberg, Andreas Herrmann, and Jan R. Landwehr (2012), "It Is All in the Mix: The Interactive Effect of Music Tempo and Mode on In-Store Sales," Marketing Letters, 23 (1), 325-37.

Kozinets, Robert V., John F. Sherry Jr., Diana Storm, Adam Duhachek, Krittinee Nuttavuthisit, and Benet DeBerry-Spence (2004), "Ludic Agency and Retail Spectacle," Journal of Consumer Research, 31 (December), 658-72.

Laurier, Eric (2008), "How Breakfast Happens in the Café," Time and Society, 17 (1), 119-34.

Leclerc, France, Bernd H. Schmitt, and Laurette Dubé (1995), "Waiting Time and Decision Making: Is Time Like Money?" Journal of Consumer Research, 22 (June), 110-19.

Levine, Robert N. (2008), A Geography of Time: On Tempo, Culture, and the Pace of Life, New York: Basic Books.

Lyng, Stephen (1990), "Edgework: A Social Psychological Analysis of Voluntary Risk Taking," American Journal of Sociology, 95 (4), 851-86.

Magaudda, Paolo (2011), “When Materiality 'Bites Back': Digital
Music Consumption Practice in the Age of Dematerialization," Journal of Consumer Culture, 11 (1), 15-36.

Maister, David H. (1985), "The Psychology of Waiting Lines," in The Service Encounter: Managing Employee/Customer Interaction in Service Businesses, ed. John A. Czepiel, Michael R. Solomon, and Carol F. Surprenant, Lexington, MA: Lexington Books, 113-23.

Martin, Diane M., and John W. Schouten (2014), "ConsumptionDriven Market Emergence," Journal of Consumer Research, 40 (February), 855-70.

Merchant, Stephanie (2011), "The Body and the Senses: Visual Methods, Videography and the Submarine Sensorium," Body and Society, 17 (1), 53-72.

Merleau-Ponty, Maurice (1962), Phenomenology of Perception, London: Routledge.

Miller, Elizabeth Gelfand, Barbara E. Kahn, and Mary Frances Luce (2008), "Consumer Wait Management Strategies for Negative Service Events: A Coping Approach," Journal of Consumer Research 34 (February), 635-48.

Milliman, Ronald E. (1982), "Using Background Music to Affect the Behavior of Supermarket Shoppers," Journal of Marketing, 46 (Summer), 86-91.

___ (1986), "The Influence of Background Music on the Behavior of Restaurant Patrons," Journal of Consumer Research, 13 (September), 286-89.

Nandy, Ashis (2000) The Tao of Cricket: On Games of Destiny and Destiny of Games, New Delhi: Oxford University Press.

Oakes, Steve (2003), "Musical Tempo and Waiting Perceptions," Psychology and Marketing, 20 (8), 685-705.

Okada, Erica M., and Stephen J. Hoch (2003), "Spending Time versus Spending Money," Journal of Consumer Research, 31 (2), 313-23.

Parkins, Wendy (2004) "Out of Time: Fast Subjects and Slow Living," Time and Society, 13 (2-3), 363-82.

Pink, Sarah (2007), "Sensing Cittàslow: Slow Living and the Constitution of the Sensory City," Senses and Society, 2 (1), 59-78.

Reckwitz, Andreas (2002a), "Toward a Theory of Social Practices: A Development in Culturalist Theorizing," European Journal of Social Theory, 5 (2), 243-65.

(2002b), "The Status of the Material in Theories of Culture: From Social Structure to Artefacts," Journal for the Theory of Social Behaviour, 32 (2), 195-217.

Ritzer, George (1999) Enchanting a Disenchanted World: Revolutionizing the Means of Consumption, Thousand Oaks, CA: Pine Oaks.

Seale, Clive (1999), "Quality in Qualitative Research," Qualitative Research, 5 (4), 465-78.

Schau, Hope J., Mary C. Gilly, and Mary Wolfinbarger (2009), "Consumer Identity Renaissance: The Resurgence of IdentityInspired Consumption in Retirement," Journal of Consumer Research, 36 (August), 255-76.

Schau, Hope J., Albert M. Muñiz, and Eric J. Arnould (2009), "How Brand Community Practices Create Value," Journal of Marketing, 73 (September), 30-51.

Schatzki, Theodore R. (1997), "Practices and Actions: A Wittgensteinian Critique of Bourdieu and Giddens," Philosophy of the Social Sciences, 27 (3), 283-308.

(2002), The Site of the Social: A Philosophical Account of the Constitution of Social Life and Change, University Park: Pennsylvania State University Press.

(2009), "Timespace and the Organization of Social Life," in Time, Consumption and Everyday Life: Practice, Materi- 
ality and Culture, ed. Elizabeth Shove, Frank Trentmann, and Richard Wilk, New York: Berg, 35-48.

(2010), The Timespace of Human Activity: On Performance, Society, and History as Indeterminate Teleological Events, New York: Lexington Books.

Schouten, John W., and James H. McAlexander (1995), "Subcultures of Consumption: An Ethnography of the New Bikers," Journal of Consumer Research, 22 (1), 43-61.

Schön, Donald (1983), The Reflective Practitioner: How Professionals Think in Action, New York: Basic Books.

Sherry, John (1998), ServiceScapes: The Concept of Place in Contemporary Markets, Lincolnwood, IL: NTC Business Books.

Shove, Elizabeth, and Mika Pantzar (2005), "Consumers, Producers and Practices: Understanding the Invention and Reinvention of Nordic Walking," Journal of Consumer Culture, 5 (1), 43-64.

Shove, Elizabeth, Mika Pantzar, and Matt Watson (2012), The Dynamics of Social Practice: Everyday Life and How It Changes, London: Sage.

Shove, Elizabeth, Frank Trentmann, and Richard Wilk (2009), Time, Consumption and Everyday Life: Practice, Materiality and Culture, Oxford: Berg.

Southerton, Dale (2006), "Analysing the Temporal Organization of Daily Life," Sociology, 40 (3), 435-54.

Spangenberg, Eric R., Ayn E. Crowley, and Pamela W. Henderson (1996), "Improving the Store Environment: Do Olfactory Cues Affect Evaluations and Behaviors?" Journal of Consumer Research, 60 (April), 67-80.

Stern, David (2002), "Sociology of Science, Rule Following and Forms of Life," in History of Philosophy of Science-New Trends and Perspectives, ed. M. Heidelberger and F. Stadler, Amsterdam: Kluwer, 347-67.

Taylor, Shirley (1994), "Waiting for Service: The Relationship between Delays and Evaluations of Service," Journal of Marketing, 58 (April), 56-69.
Thomas, Tandy C., Linda L. Price, and Hope J. Schau (2013), "When Differences Unite: Resource Dependance in Heterogeneous Consumption Communities," Journal of Consumer Research, 39 (5), 1010-33.

Toyoki, Sammy, Alexandre Schwob, Joel Hietanen, and Rasmus Johnsen (2013), "Bringing the Body Back into the Study of Time in Consumer Research," in Research in Consumer Behavior, Vol. 15, ed. Russ Belk, Linda Price, and Lisa Peñaloza, Bingley: Emerald Group Publishing, 227-44.

Truninger, Monica (2011), "Cooking with Bimby in a Moment of Recruitment: Exploring Conventions and Practice Perspectives," Journal of Consumer Culture, 11 (1), 37-59.

Tsai, Claire I., and Min Zhao (2011), "Predicting Consumption Time: The Role of Event Valence and Unpackaging," Journal of Consumer Research, 38 (October), 459-73.

Usunier, Jean-Claude, and Pierre Valette-Florence (2007), "The Time Styles Scale: A Review of Developments and Replications over 15 Years," Time and Society, 16 (2-3), 333-66.

Valtonen, Anu, Vesa Markuksela, and Johanna Moisander (2010), "Doing Sensory Ethnography in Consumer Research," International Journal of Consumer Studies, 34 (4), 375-80.

Wallendorf, Melanie, and Eric J. Arnould (1991), "We Gather Together': Consumption Rituals of Thanksgiving Day," Journal of Consumer Research, 18 (June), 13-31.

Wang, Sean Yung-hsiang (2008), "Lost in Time: The Concept of Tempo and Character in the Music of Brahms," PhD dissertation, Stanford University, Ann Arbor, MI: University Microfilms International.

Warde, Alan (2005), "Consumption and Theories of Practice," Journal of Consumer Culture, 5 (2), 131-53.

- (2013), "What Sort of a Practice Is Eating?" in Sustainable Practice: Social Theory and Climate Change, ed. Elizabeth Shove and Nicola Spurling, London: Routledge, 17-30. 